\title{
TRAVEL TIMES, APPARENT VELOCITIES AND AMPLITUDES OF BODY WAVES
}

\author{
By Bruce R. Julian and Don L. Anderson
}

\section{ABSTRACT}

Surface wave studies have shown that the transition region of the upper mantle, Bullen's Region C, is not spread uniformly over some $600 \mathrm{~km}$ but contains two relatively thin zones in which the velocity gradient is extremely high. In addition to these transition regions which start at depths near 350 and $650 \mathrm{~km}$, there is another region of high velocity gradient which terminates the lowvelocity zone near $160 \mathrm{~km}$. Theoretical body wave travel time and amplitude calculations for the surface wave model CITIIGB predict two prominent regions of triplication in the travel-time curves between about $15^{\circ}$ and $40^{\circ}$ for both $P$ and $S$ waves, with large amplitude later arrivals. These large later arrivals provide an explanation for the scatter of travel time data in this region, as well as the varied interpretations of the " $20^{\circ}$ discontinuity."

Travel times, apparent velocities and amplitudes of $P$ waves are calculated for the Earth models of Gutenberg, Lehmann, Jeffreys and Lukk and Nersesov. These quantities are calculated for both $P$ and $S$ waves for model CITIIGB. Although the first arrival travel times are similar for all the models except that of Lukk and Nersesov, the times of the later arrivals differ greatly. The neglect of later arrivals is one reason for the discrepancies among the body wave models and between the surface wave and body wave models.

The amplitude calculations take into account both geometric spreading and anelasticity. Geometric spreading produces large variations in the amplitude with distance, and is an extremely sensitive function of the model parameters, providing a potentially powerful tool for studying details of the Earth's structure. The effect of attenuation on the amplitudes varies much less with distance than does the geometric spreading effect. Its main effect is to reduce the amplitude at higher frequencies, particularly for $S$ waves, which may account for their observed low frequency character.

Data along a profile to the northeast of the Nevada Test Site clearly show a later branch similar to the one predicted for model CITI1GB, beginning at about $12^{\circ}$ with very large amplitudes and becoming a first arrival at about $18^{\circ}$. Strong later arrivals occur in the entire distance range of the data shown, $11 \frac{1}{2}^{\circ}$ to $21^{\circ}$. Two models are presented which fit these data. They differ only slightly and confirm the existence of discontinuities near 400 and 600 kilometers.

A method is described for predicting the effect on travel times of small changes in the Earth structure.

\section{INTRODUCTION}

Most of our present knowledge about the Earth's interior has come from the study of seismic body waves. These studies have, however, been largely confined to the travel times of first arriving waves. Because of lack of attention to later 
arrivals, such problems as the nature of the " $20^{\circ}$ discontinuity" still remain unresolved. Furthermore, considerable additional information can be derived by consideration of parameters other than travel time, such as apparent velocity, which can now be measured directly with large seismometer arrays, and amplitude.

Recently surface waves have supplied an independent view of the structure of the upper mantle that is in substantial agreement with the gross features of some of the standard body wave models. Surprisingly, however, some fine structure of the upper mantle has been recognized which is missing in the body wave structures. Surface waves are generally regarded as being sensitive only to gross properties, whereas body waves are more sensitive to structural details, so it is important to resolve the discrepancy between surface wave and body wave interpretations. It is the purpose of this paper to resolve the apparent discrepancy, both by pointing out the reasons for the difficulties with body wave analysis in the epicentral distance range $10^{\circ}$ to $30^{\circ}$ and by utilizing the later arrivals predicted from the surface wave models.

A variety of factors are contributing to an increased emphasis on the use of body waves for detailed studies of the Earth's deep interior. These include the improved coverage of the Earth's surface with standardized instruments and arrays, the use of accurately timed and located large explosions as seismic sources, and the increased accuracy and convenience of data processing with large digital computers. Besides making available improved precision and better coverage for the standard methods of seismic body wave analysis, these factors make possible more complete use of previously unexploited parameters such as apparent velocity, polarization and amplitude.

\section{Theoretical Body Wave Calculations}

In order to study the behavior of these additional parameters, programs have been written for the IBM 7094 digital computer which calculate travel times, apparent velocities and amplitudes of body waves in a spherically symmetric, isotropic earth. The calculations are based on geometrical ray theory (see, for example, Bullen, 1963, Ch. 7). Both geometric spreading and attenuation due to anelasticity are taken into account in calculating amplitudes. The method of calculation is described in the Appendix. As a first step in a more complete attack on the problem of the velocity structure of the Earth's interior, we have calculated the travel times, apparent velocities, and amplitudes for the standard Earth models and several more recent models, based upon both surface wave and body wave studies.

Earth Models. Besides the low-velocity zone, the main features of the mantle that are required to satisfy surface wave data are relatively thin transition regions near 160, 350, and 650 kilometers (Anderson and Toksöz, 1963). Although high velocity gradients in the upper mantle are features of the standard body wave mantle models of Gutenberg, Jeffreys and Lehmann, only the model of Lehmann contains a discontinuity in this region. The upper mantle $P$ wave velocities for the models of Gutenberg, Jeffreys and Lehmann are given in Figure 1. The general features of these models are well known. Both the Gutenberg and Lehmann models have a low-velocity zone in the upper mantle. There is a first order discontinuity at $215 \mathrm{~km}$ in Lehmann's model, and below it a smooth increase which joins onto 
Jeffreys' model near $700 \mathrm{~km}$. The Gutenberg model has no strong 1st or 2nd order discontinuities, but has a high-velocity gradient from the low-velocity zone to about $900 \mathrm{~km}$. The Jeffreys model has no low velocity zone but has a second order discontinuity near $415 \mathrm{~km}$. Also shown is a recent body wave structure proposed by Lukk and Nersesov (1965) and a surface wave model, CIT11GB. This latter model has a low-velocity zone and regions of extremely high-velocity gradients between $100-170,350-450$, and $650-750 \mathrm{~km}$. This structure is similar to the oceanic model

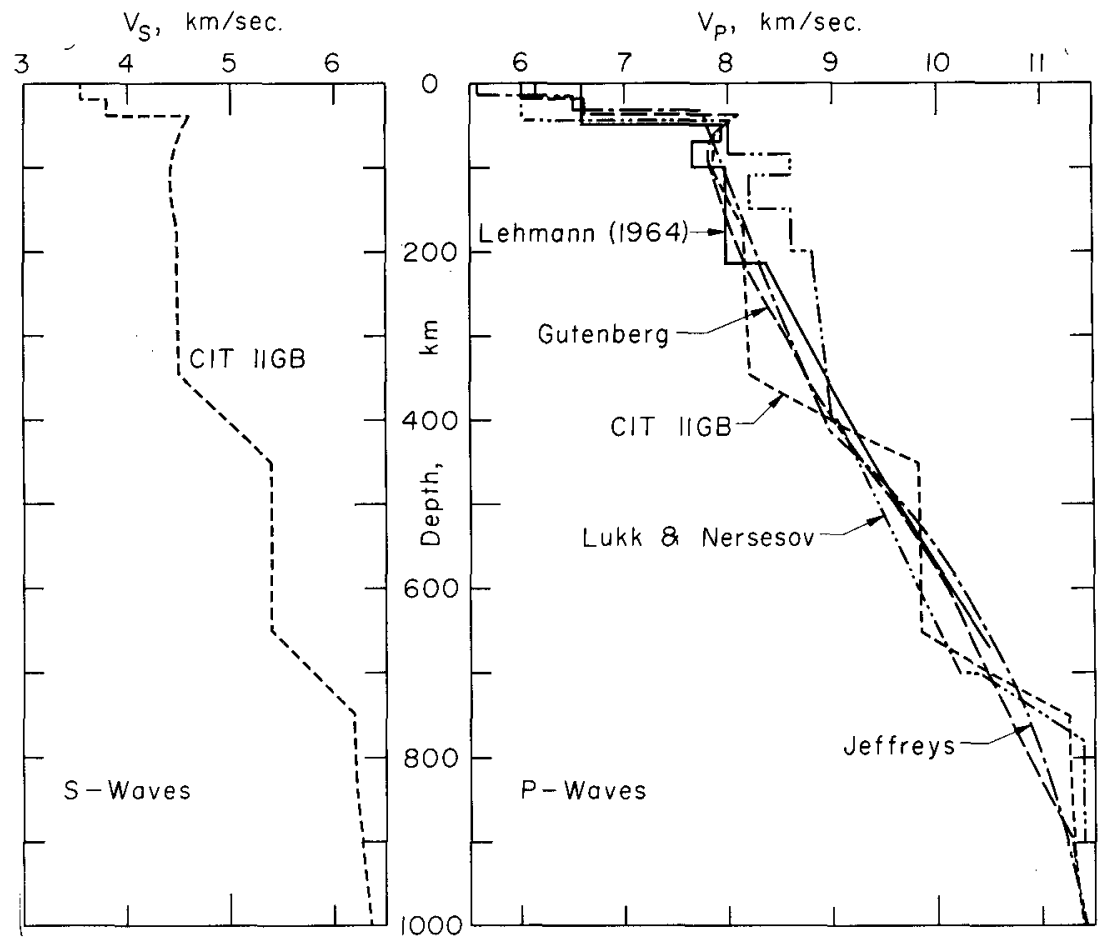

FIG. 1. Upper mantle $P$ wave velocity distribution for the models of Jeffreys, Gutenberg, Lehmann, and Lukk and Nersesov, and both $P$ and $S$ wave velocity for model CIT11GB.

CIT11 of Anderson and Toksöz (1963), but has been modified to have a continental type crust and upper mantle. The shear wave velocities were determined from Love wave dispersion, and the $P$-wave velocities were derived from them using the Poisson's ratio distribution of Gutenberg's model.

Model CIT11 GB. The travel-time curves, geometric spreading, attenuation, and other body wave parameters were calculated for the model CIT11GB and are shown in Figures 2-8. On all the travel-time curves presented here, the JeffreysBullen times have been indicated by dots for the sake of comparison. Multibranched travel-time curves, with large amplitude later arrivals, are important features of this and similar models. For $P$ waves (Figure 2 ), the low-velocity zone produces a shadow zone which ends with a small reverse branch between $12.2^{\circ}$ and $13.2^{\circ}$. Between $14.3^{\circ}$ and $31.8^{\circ}$ there is a region of triplication $(\mathrm{B}-\mathrm{C})$ produced by the 
discontinuity at $350-450 \mathrm{~km}$, and similarly the discontinuity at $650-750 \mathrm{~km}$ produces an overlapping triplication ( $\mathrm{D}-\mathrm{E}$ ) between $21.1^{\circ}$ and $40.2^{\circ}$. There is also a small zone of triplication near $39^{\circ}$, produced by a small second order discontinuity at $850 \mathrm{~km}$. The travel-time curve for $S$ waves (Figure 4 ) is similar, the main difference being that the first ray to penetrate below the low velocity zone emerges

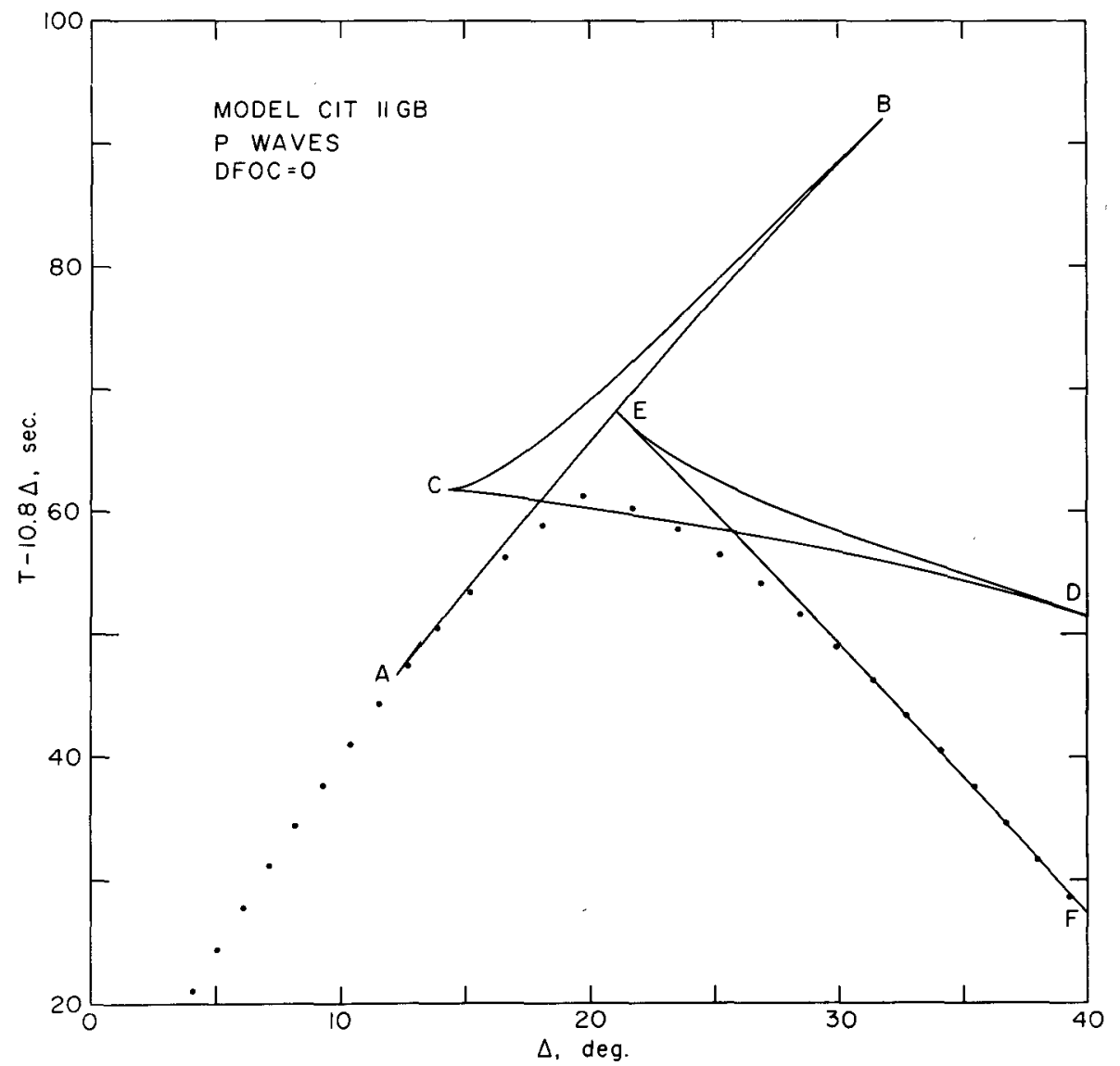

Frg. 2. Reduced $P$-wave travel times for model CIT11GB. Surface focus. Dots indicate JeffreysBullen times. Letters are for correlation with Figures 3, 6, 8 .

at a greater distance, $25.4^{\circ}$. Slight changes in the model either above or below the low-velocity zone could change this result, however. As with $P$ waves, there are two overlapping regions of triplication: one between $14.5^{\circ}$ and $34.1^{\circ}$ (B-C), produced by the $350 \mathrm{~km}$ discontinuity, and one between $21.1^{\circ}$ and $41.3^{\circ}(\mathrm{D}-\mathrm{E})$, produced by the $650 \mathrm{~km}$ discontinuity. If first arrivals alone are considered, the travel-time curve for $P$ can be considered to be made up of three approximately straight line segments, with apparent velocities of about $8.4,10.7$, and $12.9 \mathrm{~km} / \mathrm{sec}$, intersecting at $18^{\circ}$ and $25.7^{\circ}$. The first arrival curve for $S$ waves consists of two branches, with velocities of about 5.8 and $7.0 \mathrm{~km} / \mathrm{sec}$, intersecting at $25.8^{\circ}$. 
Geometric spreading has a very pronounced effect on the amplitude of body waves. In the distance range $0^{\circ}-40^{\circ}$, this effect varies by a factor of about 100 for both $P$ and $S$ waves (Figures 3,5 ). The amplitude is particularly large for the upper branches near the cusps at the beginning of regions of triplication. Slightly rounding the bottoms of the discontinuities (at 450 and $750 \mathrm{~km}$ ) would produce large amplitudes on both branches near these cusps.

Attenuation. In addition to the geometric spreading effect, for model CIT11GB

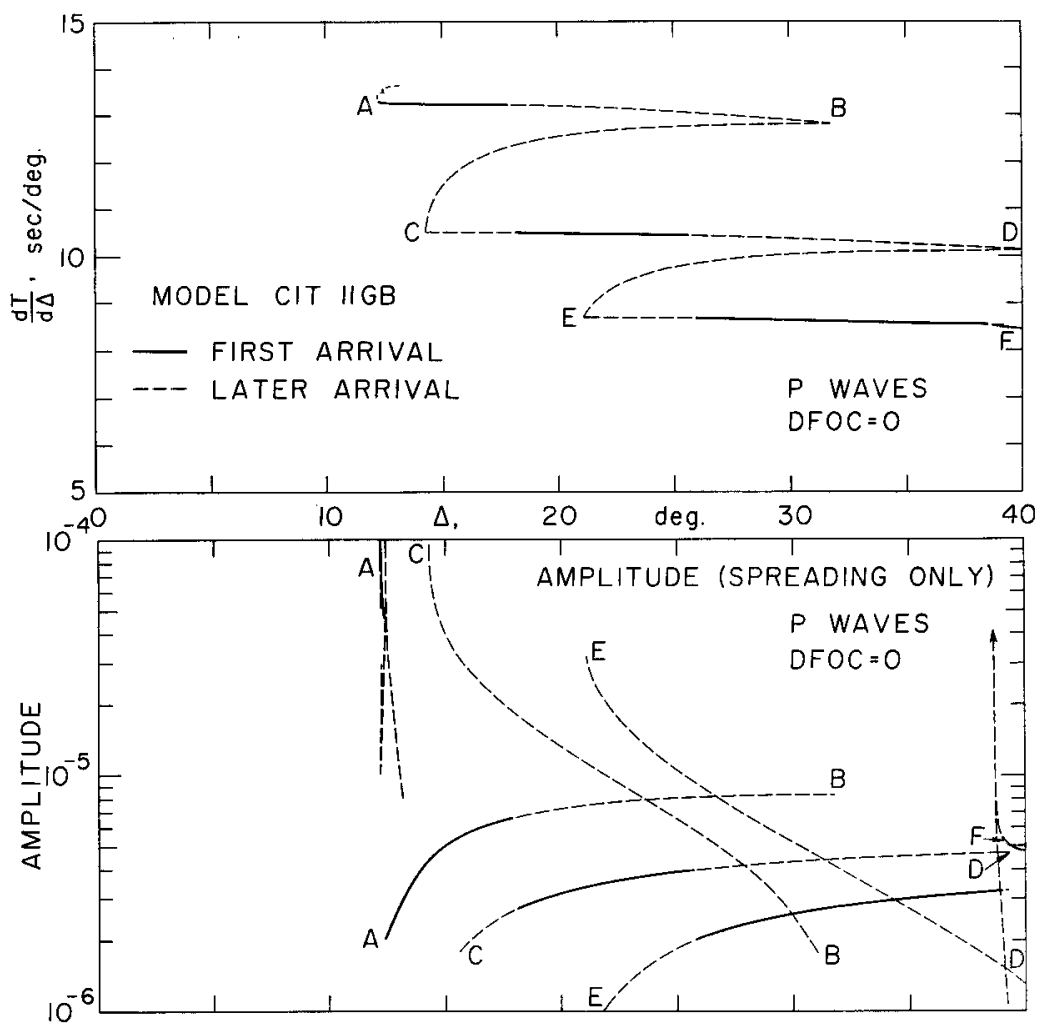

FIG. 3. Slope of travel-time curve, $d T / d \Delta$, and amplitude, considering geometric spreading only, for $P$ waves in model CIT11GB. Surface focus. Letters are for correlation with Figures $2,6,8$.

the effect upon the amplitude of attenuation due to anelasticity has been calculated. The $Q$ versus depth structure used was model MM8 of Anderson et al (1965), derived from surface wave attenuation. In order to determine whether the slight attenuation may account for the observed low frequency character of $S$ waves. been attenuated strongly in the upper mantle, the calculations were done for two versions of the $Q$ model: one with the values given by Anderson et al below $600 \mathrm{~km}$ ( $Q=4500$ for $P$ waves, $Q=2000$ for $S$ waves), and the other with infinite $Q$ (no attenuation) in this region. For a particular frequency, the main effect of anelasticity is to decrease the amplitude with increasing distance in the region of triplications between $10^{\circ}$ and $40^{\circ}$, where the rays are affected most strongly by 
the low $Q$ upper mantle (Figure 6). For rays penetrating below $750 \mathrm{~km}$ (branches $\mathrm{E}-\mathrm{F}$, Figure 6 ), the attenuation depends very little on distance.

Compared to the effect of geometric spreading, the effect of attenuation on the amplitude versus distance curves is slight, except for high frequencies which are so greatly attenuated as to be difficult to observe. The most significant effect of attenuation, in fact, is upon amplitude as a function of frequency, which is shown

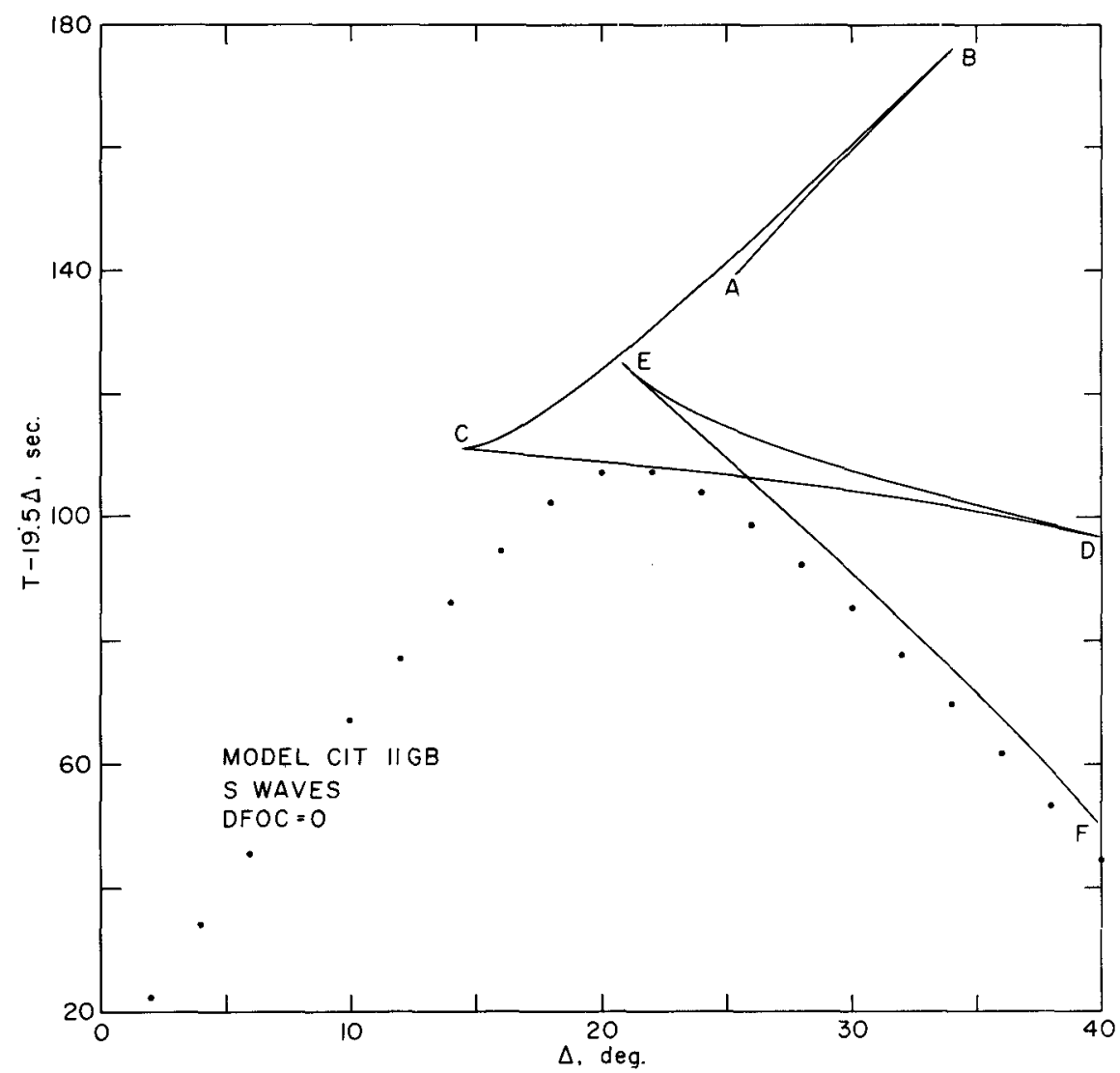

FIG. 4. Reduced S-wave travel times for model CIT11GB. Surface focus. Dots indicate JeffreysBullen times. Letters are for correlation with Figures 5, 6, 8 .

in Figure 7 for several points from Figure 6. Immediately apparent is the greater attenuation at high frequencies of $S$ waves, due to both their lower $Q$ and their greater travel time. For corresponding rays, $S$ waves are attenuated 10 to 1000 times as much as $P$ waves at $0.5 \mathrm{cps}$ and 100 to $10^{6}$ times as much at $1 \mathrm{cps}$. Thus attenuation may account for the observed low frequency character of $S$ waves. Another way of looking at amplitude versus frequency is by means of effective $Q$. From Figure 8 one can see not only that the effective $Q$ is about $2 \frac{1}{4}$ times greater for $P$ waves than for $S$ waves, but also that it varies by a factor of about 6 for both wave types. Furthermore, for the models with no attenuation in the lower mantle, the effective $Q$ is greater by as much as 30 per cent, which is easily detectable. The 


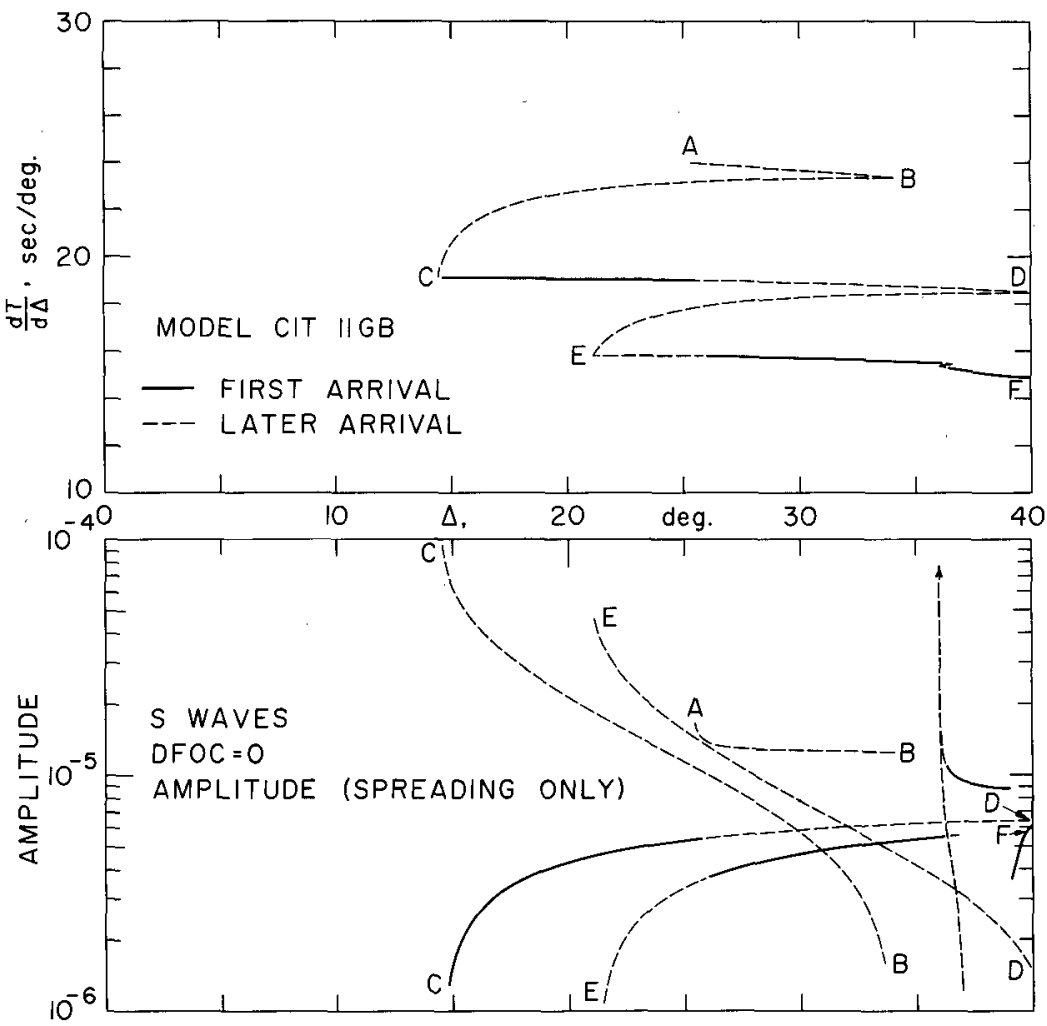

FIG. 5. $d T / d \Delta$ and amplitude, considering geometric spreading only for $S$ waves in model CIT11GB. Surface focus. Letters are for correlation with Figures 4, 6, 8 .

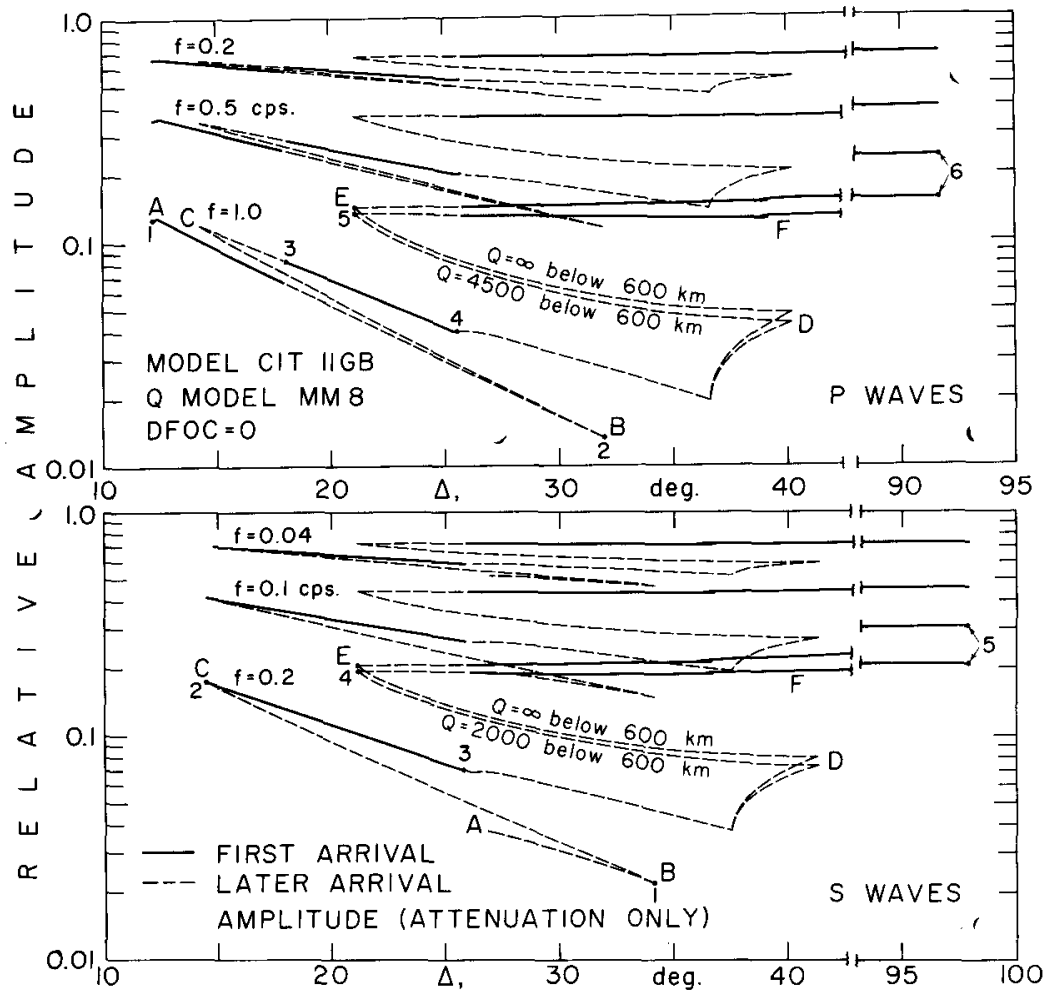

FIg. 6. Amplitude, considering attenuation only, of $P$ and $S$ waves in model CIT11GB, $Q$ model MM8. Surface focus. Letters are for correlation with Figures $2,3,4,5,8$. Numbered points correspond to lines in Figure 7. Note break in abscissa between 40 and 95 degrees. 


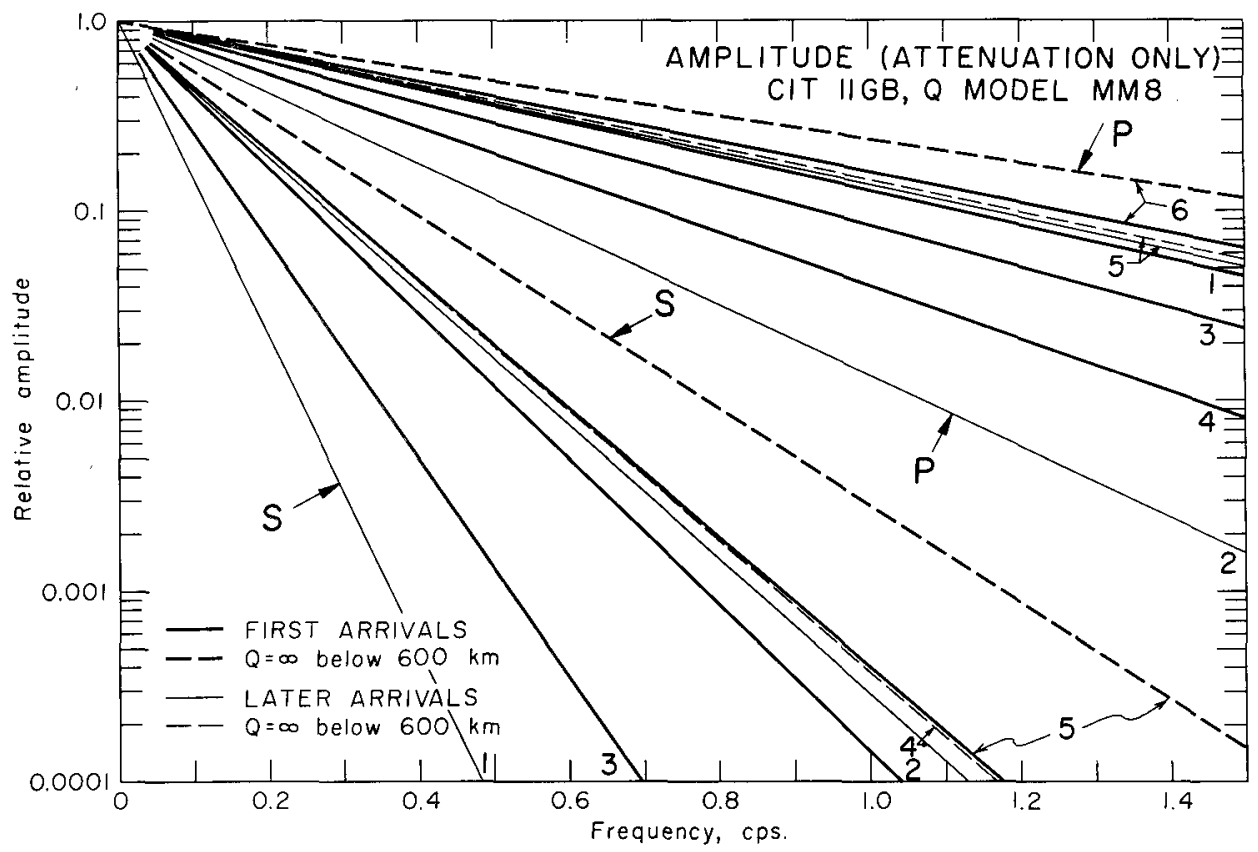

FIg. 7. Amplitude as a function of frequency, considering attenuation only, of $P$ and $S$ waves in model CIT11GB, $Q$ model MM8. Surface focus. Lines correspond to numbered points in Figure 6.

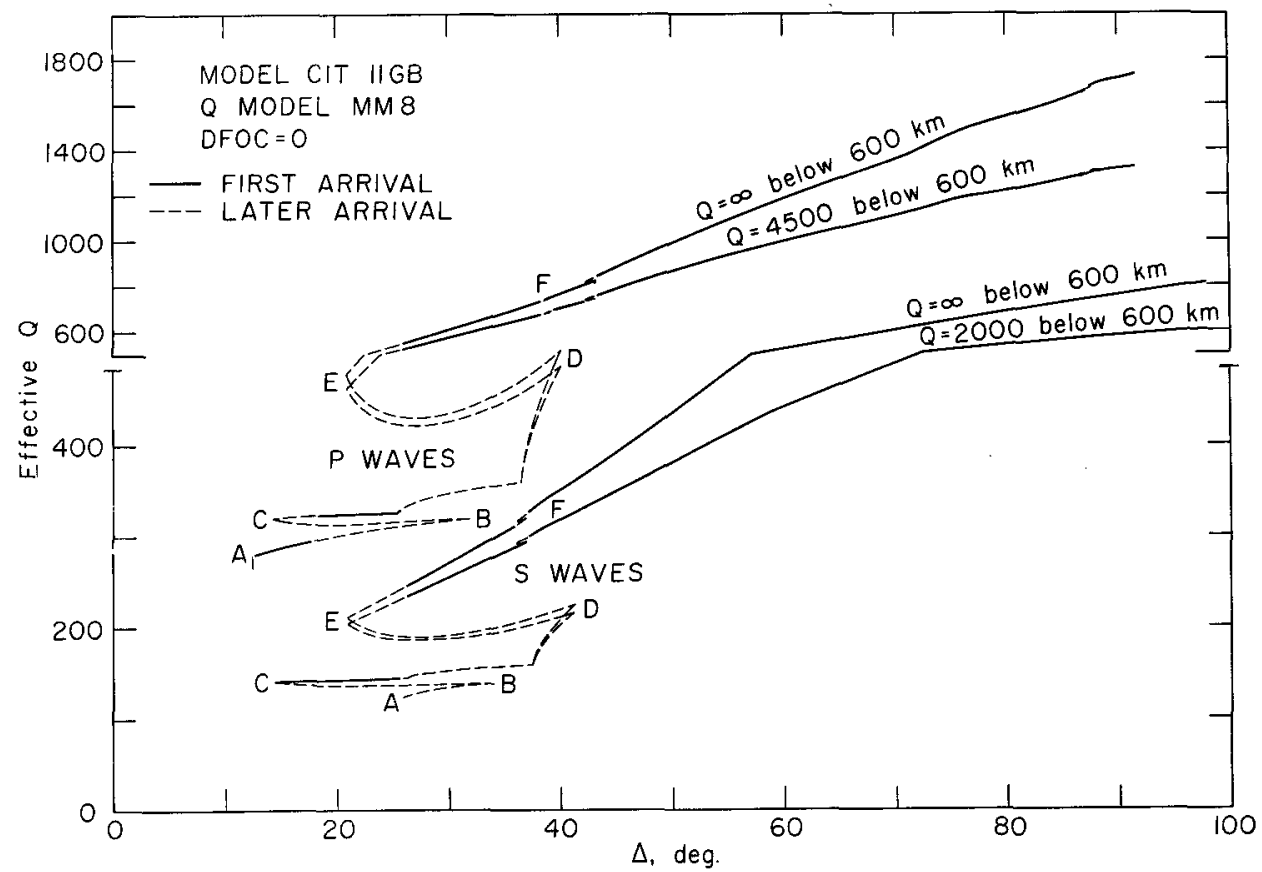

FIg. 8. Effective $Q$ for $P$ and $S$ waves in model CIT11GB, $Q$ model MM8. Surface focus. Letters are for correlation with Figures $2,3,4,5,6$. Note change in vertical scale at $Q=500$. 
lower $Q$ upper mantle does not completely mask our view of the $Q$ structure of the lower mantle.

Ray Plots. An option of the travel-time computer program described in the appendix is to plot the trajectories of rays. For example, Figures 9 and 10 give the trajectories for $P, S, P K P, S K S, P K I K P$ and $S K I K S$ in Jeffreys' Earth model. The core shadow zone for $P$ and the strong focusing of $P$ wave energy near $145^{\circ}$ are shown quite dramatically. Plots of this sort have proved quite useful in recognizing potential difficulties of interpretation and in "steering" rays in the process of model modifications.

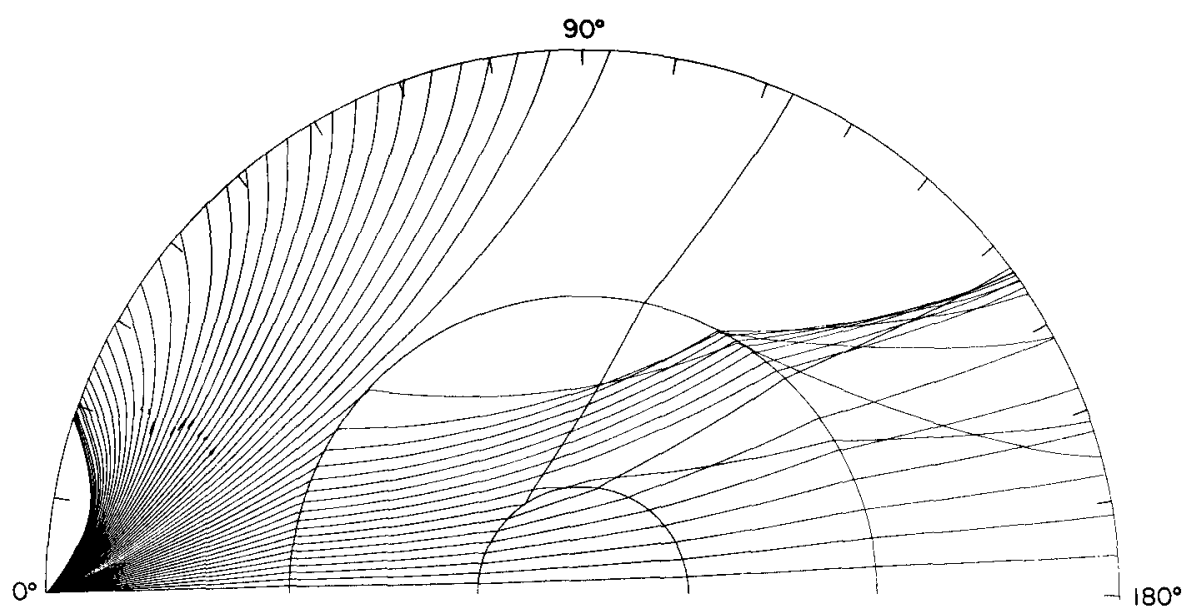

$$
\begin{aligned}
& \text { JEFFREYS MODEL P, PKP, PKIKP } \\
& \text { DFOC }=35 \mathrm{~km} \\
& \text { TOA }=1,1,51
\end{aligned}
$$

FIg. 9. Ray paths for $P, P K P$, and $P K I K P$ in Jeffreys' Earth model. Depth of focus $=35 \mathrm{~km}$. Take-off angle varies from $1^{\circ}$ to $51^{\circ}$ in $1^{\circ}$ increments.

The $P$ - and $S$-wave ray paths for model CIT11GB are shown in Figure 11 and illustrate the strong focusing effect of the discontinuities. The difficulties of interpretation between $15^{\circ}$ and $30^{\circ}$ can be well appreciated when these figures are compared with the corresponding figures for the much smoother models.

Jeffreys Model. Figures 12 and 13 show the travel-time curve, its derivative, and the amplitude, considering the effects of geometric spreading only, for $P$ waves from a surface focus in the model of Jeffreys (1962, p. 122). Between depths of 413 and $1047 \mathrm{~km}$ the model was smoothed by the addition of points spaced approximately every $32 \mathrm{~km}$, with velocities determined by 4-point Lagrangian interpolation between the points given by Jeffreys. The travel-time curve is quite smooth except for a small region of triplication in the vicinity of $20^{\circ}$. This " $20^{\circ}$ discontinuity" is produced by the moderately rapid increase of velocity between 413 and about $600 \mathrm{~km}$ depth (Bullen's region C). The ray tracings (Figure 14) are very helpful for understanding the relationship between the earth model and the zone of triplication.

Note that, although the travel-time curve is smooth, its derivative is not, and 


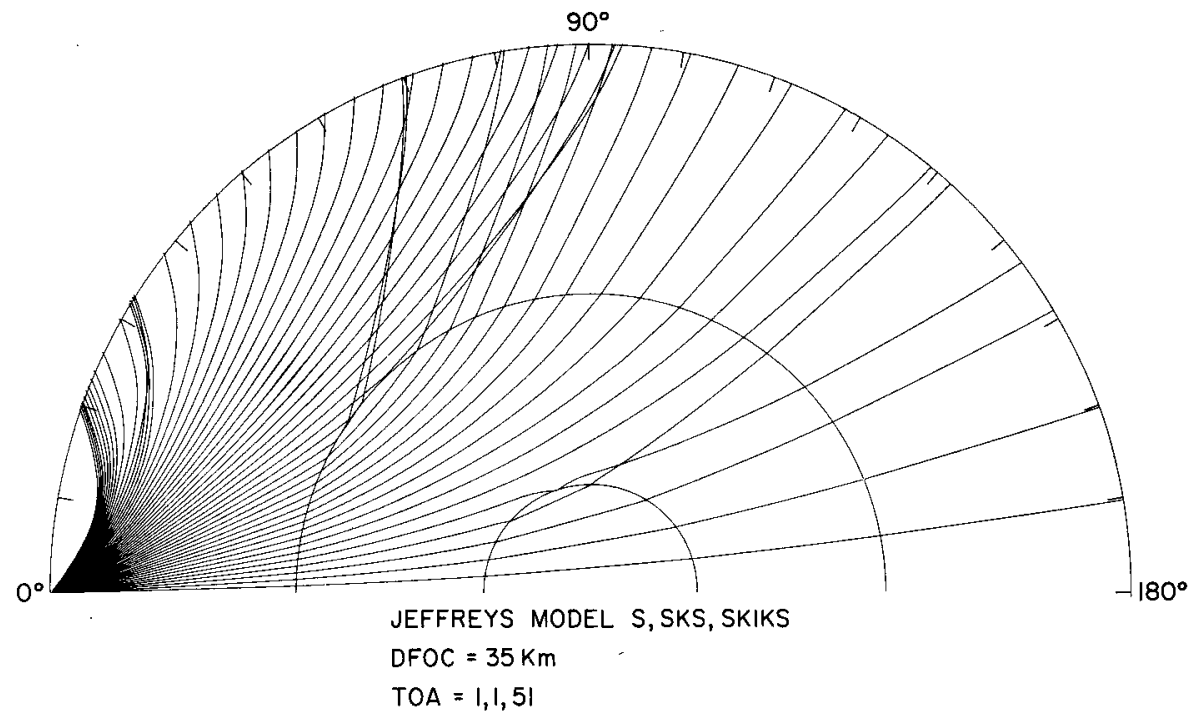

FIG. 10. Ray paths for $S, S K S$, and $S K I K S$ in Jeffreys' Earth model.

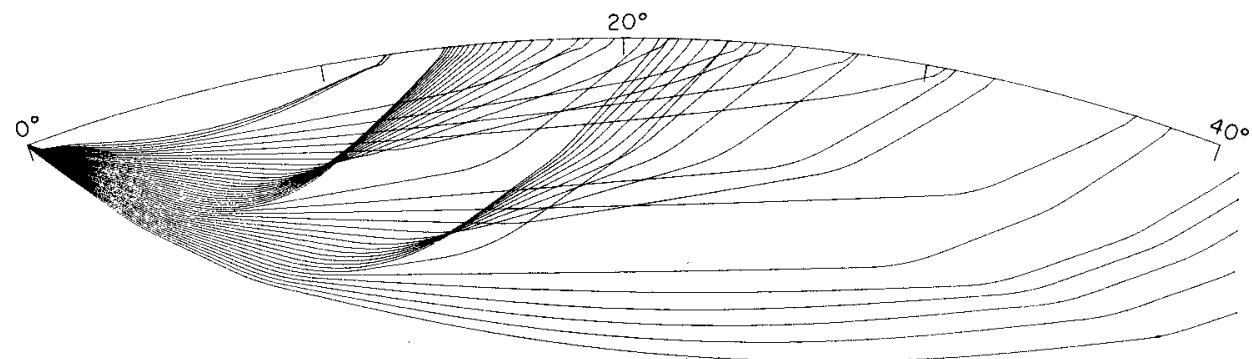

CIT IIGB MODEL, $P$

$D F O C=0$

$T O A=25,0.5,47$

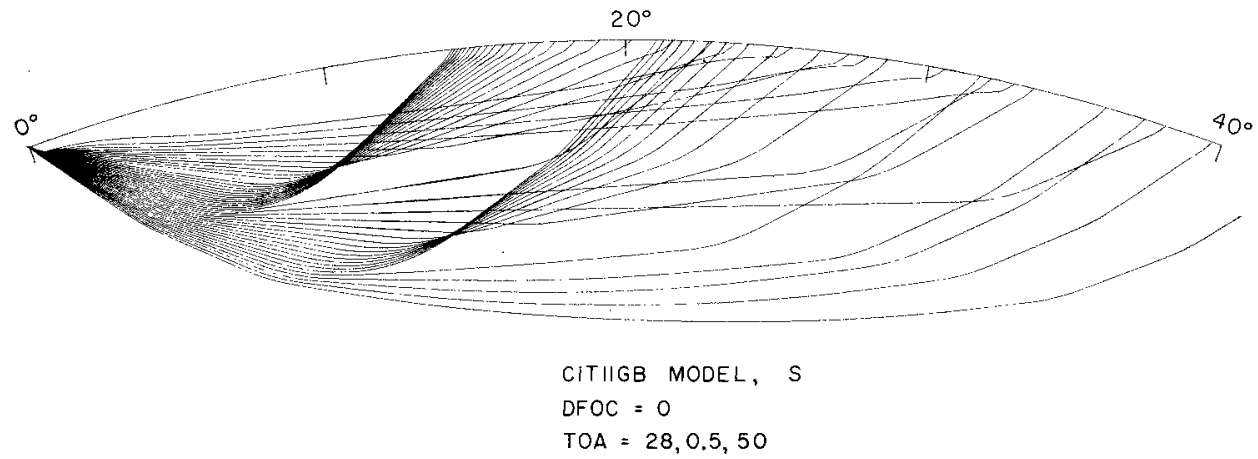

FIG. 11. Ray paths for $P$ and $S$ waves in model CIT11GB. 
the amplitude curve is discontinuous and very erratic. This behavior is caused by very slight irregularities produced by approximating the model with shells in which the velocity is given by $v=a r^{b}$. The actual behavior of body waves which have a finite wavelength is doubtless not as extremely sensitive to small irregularities as geometrical ray theory predicts. Body wave amplitude appears to be a potentially very powerful tool for studying details of Earth structure.

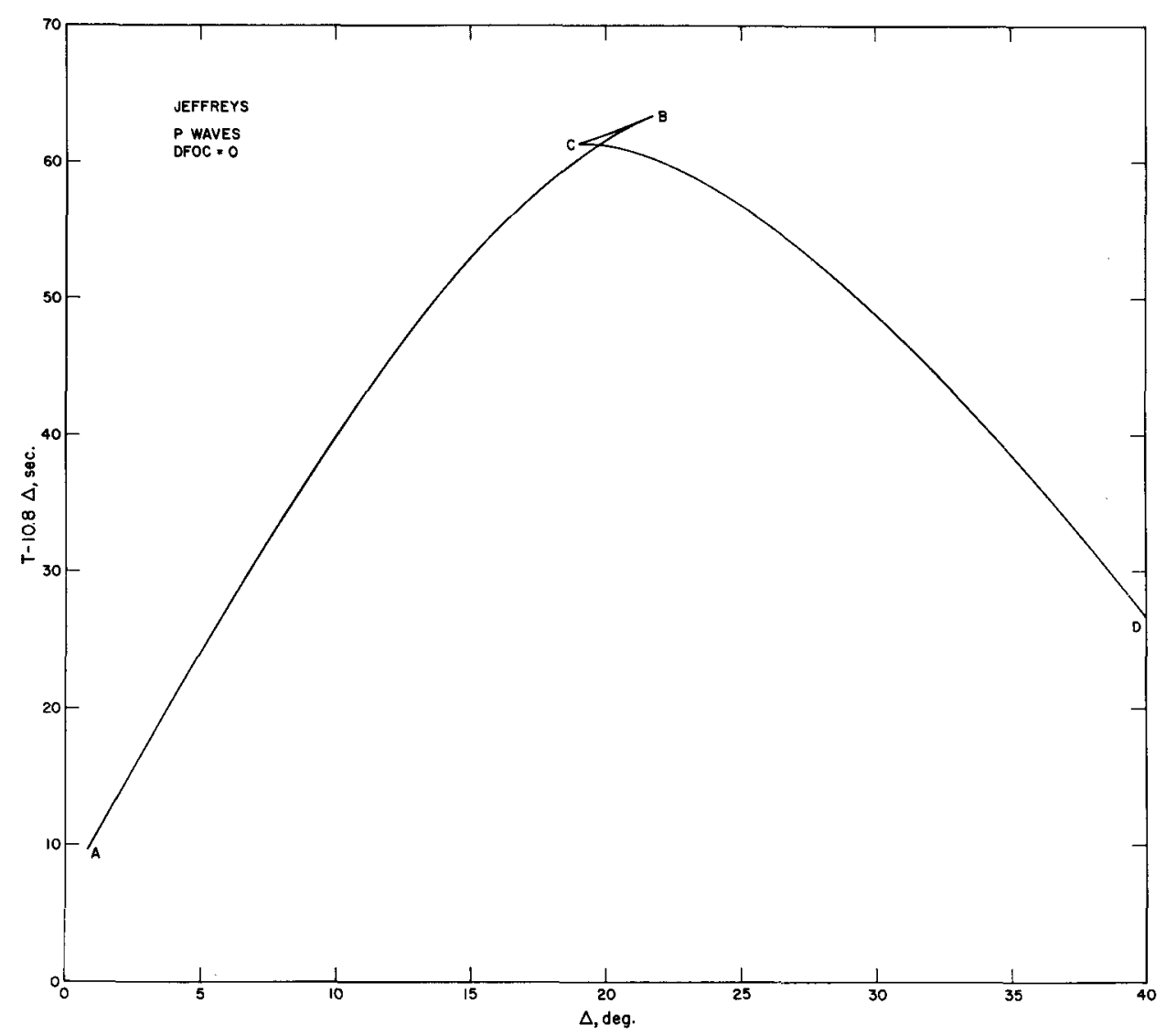

FIG. 12. Reduced $P$-wave travel times for Jeffreys model. Surface focus. Letters are for correlation with Figure 13.

Gutenberg Model. The reduced travel time, $d T / d \Delta$, and amplitude (considering geometric spreading only) of $P$ waves for the Gutenberg Earth model are shown in Figures 15 and 16. For depths less than $400 \mathrm{~km}$ the velocities were taken from Gutenberg (1959), while below $400 \mathrm{~km}$ they were taken from the tabulation of Bullard (1957). The model has, of course, the well known Gutenberg low-velocity zone, between depths of about 40 and $200 \mathrm{~km}$. This region produces a shadow zone, and immediately beyond it, a region of duplication in the travel-time curve, between 14.7 and 18.2 degrees. There are also four small zones of triplication, at 15.5 , 16.0, 18.5, and 19.1 degrees, produced by small irregularities at depths of about $225,250,350$, and $405 \mathrm{~km}$. These features, as well as the other irregularities in the 
$d T / d \Delta$ and amplitude curves are caused by small irregularities in the model, most of which are probably not significant. The drop in amplitude at $32^{\circ}$ is caused by a decrease in the velocity gradient at $900 \mathrm{~km}$, and is an important feature of this model. Again, the extreme sensitivity of the amplitudes to small details of Earth
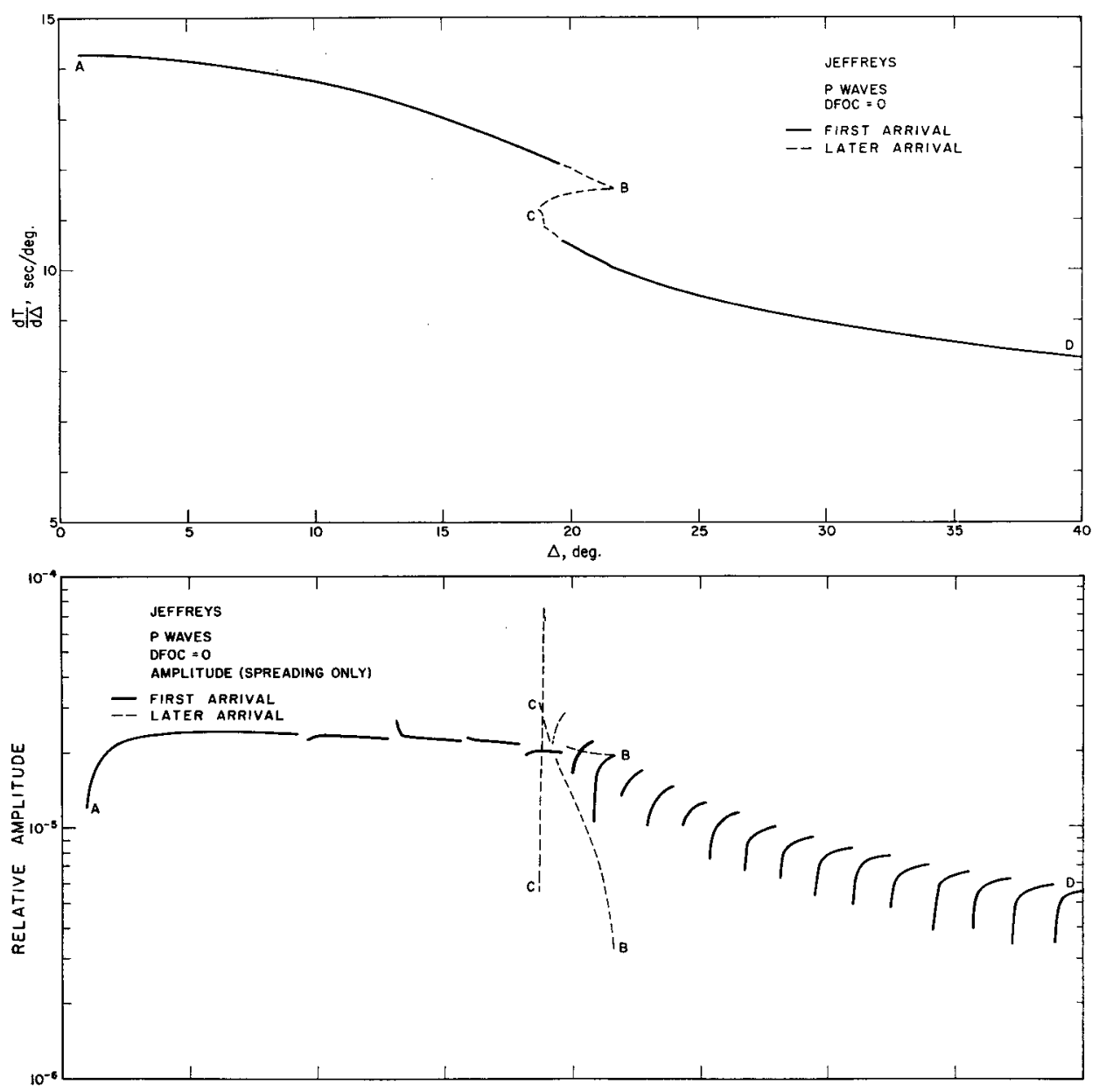

FIG. 13. $d T / d \Delta$ and amplitude, considering geometric spreading only, for $P$ waves in Jeffreys Earth model. Surface focus. Letters are for correlation with Figure 12.

structure is evident. Ray tracings for this model, shown in Figure 14 illustrate this sensitivity clearly.

Lehmann Model. Lehmann (1964) studied the travel times of $P$ waves from 14 underground nuclear explosions fired at the Nevada Test Site (NTS) in 1961 and 1962, and from the Gnome underground explosion, fired in SE New Mexico in 1962. The travel times used, those published in the AFTAC shot reports, include only first arrivals, except in the case of the Hardhat event, for which some later arrivals were picked. The Earth model derived by Lehmann has a low-velocity 
channel between depths of 70 and $100 \mathrm{~km}$, a discontinuous increase in velocity at $215 \mathrm{~km}$, and a smooth increase from 215 to $670 \mathrm{~km}$. Figures 17 and 18 show the travel-time curve, its derivative, and the amplitudes (considering geometric spreading only) for this model. As for the Gutenberg Earth model, there is a shadow zone, followed by a region of duplication, between 6 and 15 degrees, produced by the first order discontinuity at the bottom of the low velocity zone. Overlapping this region, there is a zone of triplication, from 9 to 26 degrees, produced by the dis-

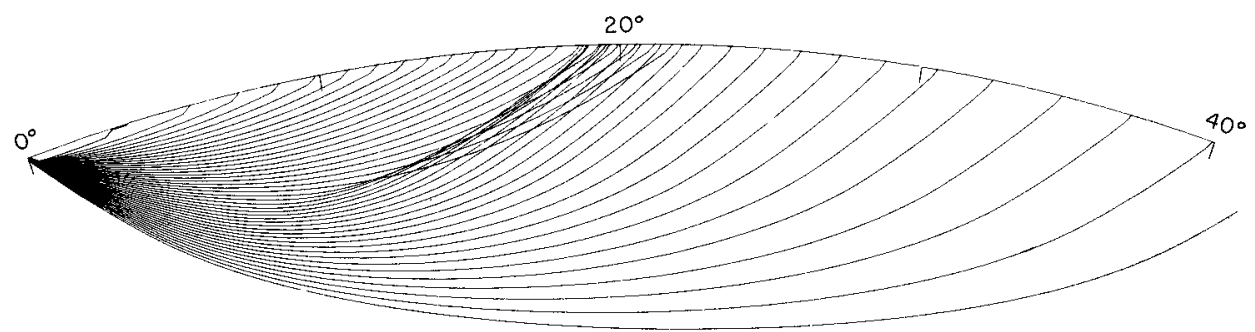

JEFFREYS MODEL, P

$D F O C=0$

TOA $=24,0.5,45.5$

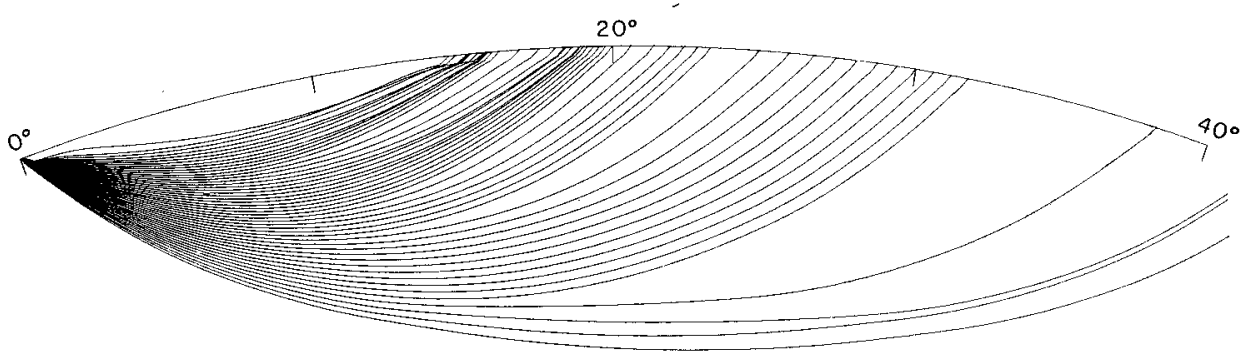

GUTENBERG (1959) MODEL, P

$D F O C=O$

$T O A=26,0.5,49$

Fig. 14. Ray paths for $P$ waves in Earth models of Jeffreys and Gutenberg.

continuity at $215 \mathrm{~km}$. The ray paths for Lehmann's model are shown in Figure 19.

Lukk and Nersesov Model. Lukk and Nerseson (1965) studied earth structure along a $3500 \mathrm{~km}$ profile extending from the Pamirs-Hindu Kush epicentral region northeast across central Asia to the Lena River. The average station spacing along the profile was 70 to $100 \mathrm{~km}$. The earth model was based on the analysis, by several different methods, of data from 240 earthquakes with focal depths between 70 and $270 \mathrm{~km}$. It has a single layer crust, $45 \mathrm{~km}$ thick, a low velocity zone between 110 and $150 \mathrm{~km}$, and discontinuous increases of velocity at $85,200,400$, and $700 \mathrm{~km}$. In addition, the velocity increases very rapidly between 700 and $780 \mathrm{~km}$, then remains constant from $780 \mathrm{~km}$ to $900 \mathrm{~km}$. For shear waves only, there is a second low-velocity channel between depths of 240 and $390 \mathrm{~km}$. Figures 20 and 21 show the travel time, $d T / d \Delta$, and amplitude, considering only geometric spreading, of $P$ 
waves from a surface focus for this model. The travel-time curve is divided into two unconnected segments, $\mathrm{A}-\mathrm{D}$ and $\mathrm{E}-\mathrm{O}$, because of the low-velocity zone. The discontinuity at $85 \mathrm{~km}$, above the low-velocity zone, produces the region of triplication $\mathrm{B}-\mathrm{C}$ in the first segment. The second segment has a region of duplication, $\mathrm{E}-\mathrm{F}$, between $8.1^{\circ}$ and $14.3^{\circ}$, produced by the bottom of the low-velocity zone, and four regions of triplication, $\mathrm{G}-\mathrm{H}\left(9.4^{\circ}-21.3^{\circ}\right)$, I-J $\left(22.6^{\circ}-29^{\circ}\right), \mathrm{K}-\mathrm{L}\left(22.5^{\circ}-\right.$

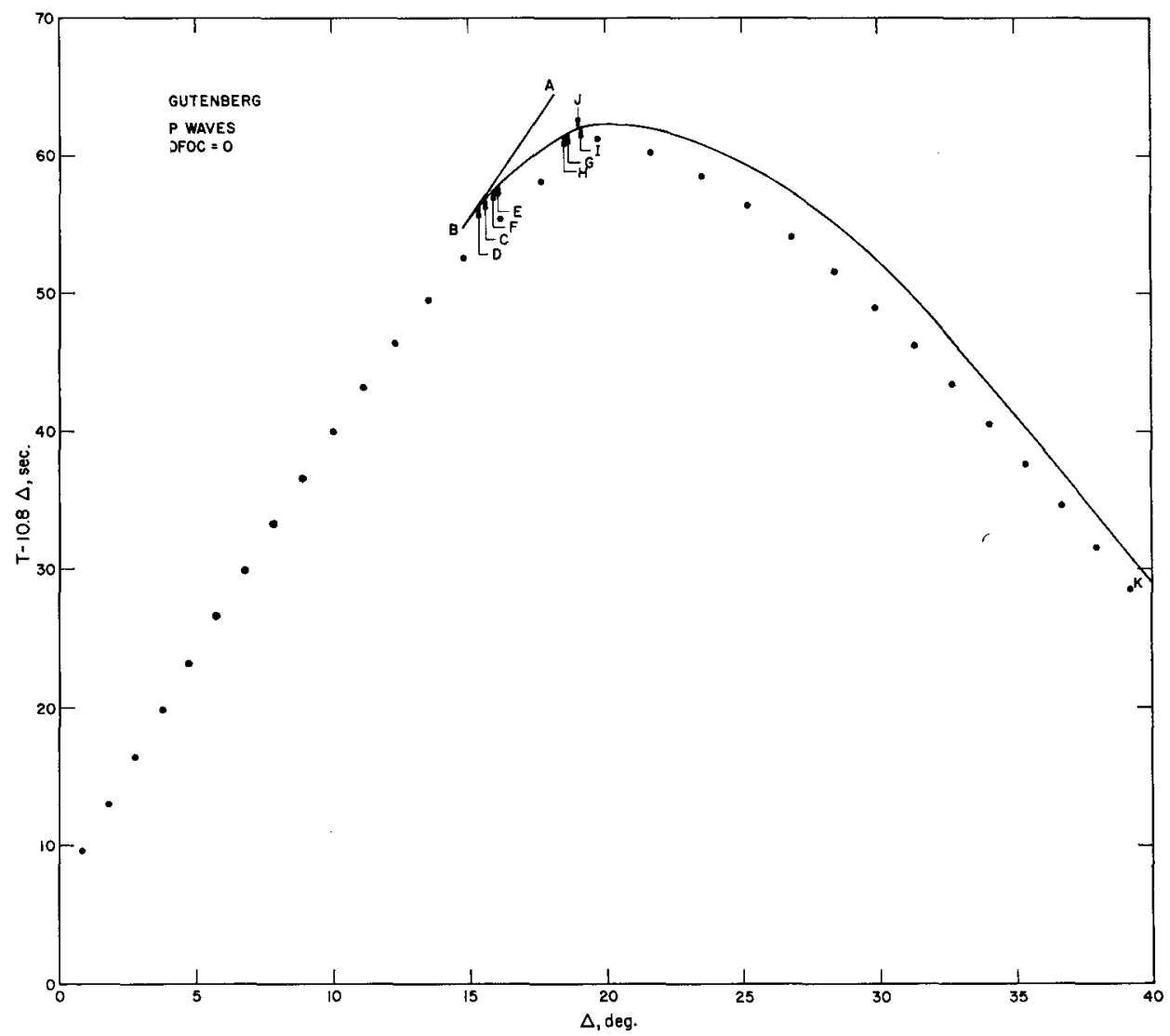

FIg. 15. Reduced $P$-wave travel times for Gutenberg Earth model. Surface focus. Dots indicate Jeffreys-Bullen times. Letters are for correlation with Figure 16.

$\left.29^{\circ}\right)$, and $\mathrm{M}-\mathrm{N}\left(22.2^{\circ}-23.3^{\circ}\right)$, produced, respectively, by discontinuities at 200 , 400 , and $700 \mathrm{~km}$ and the rapid velocity increase between 700 and $780 \mathrm{~km}$. In addition to having many complex later arrivals, this model is interesting because the first arrival travel times are not consistent with those for the other models suggesting that the earth may be significantly different in Asia than in Europe and North America. Figure 19 illustrates the ray trajectories calculated for this model.

With the exception of the model of Lukk and Nersesov, the first arrival times are similar for all the models, although the later arrivals differ considerably. Many body wave studies are based entirely on first arrivals. Because of scatter in travel-time 
data, it is difficult or impossible, using first arrivals alone, to distinguish between a smooth curve, such as that for Jeffreys' model (Figure 12), and one with sharp bends. If a smooth curve were fitted to the first arrivals of a travel-time curve similar to Figure 2, a velocity structure would result which is similar to Jeffreys'.
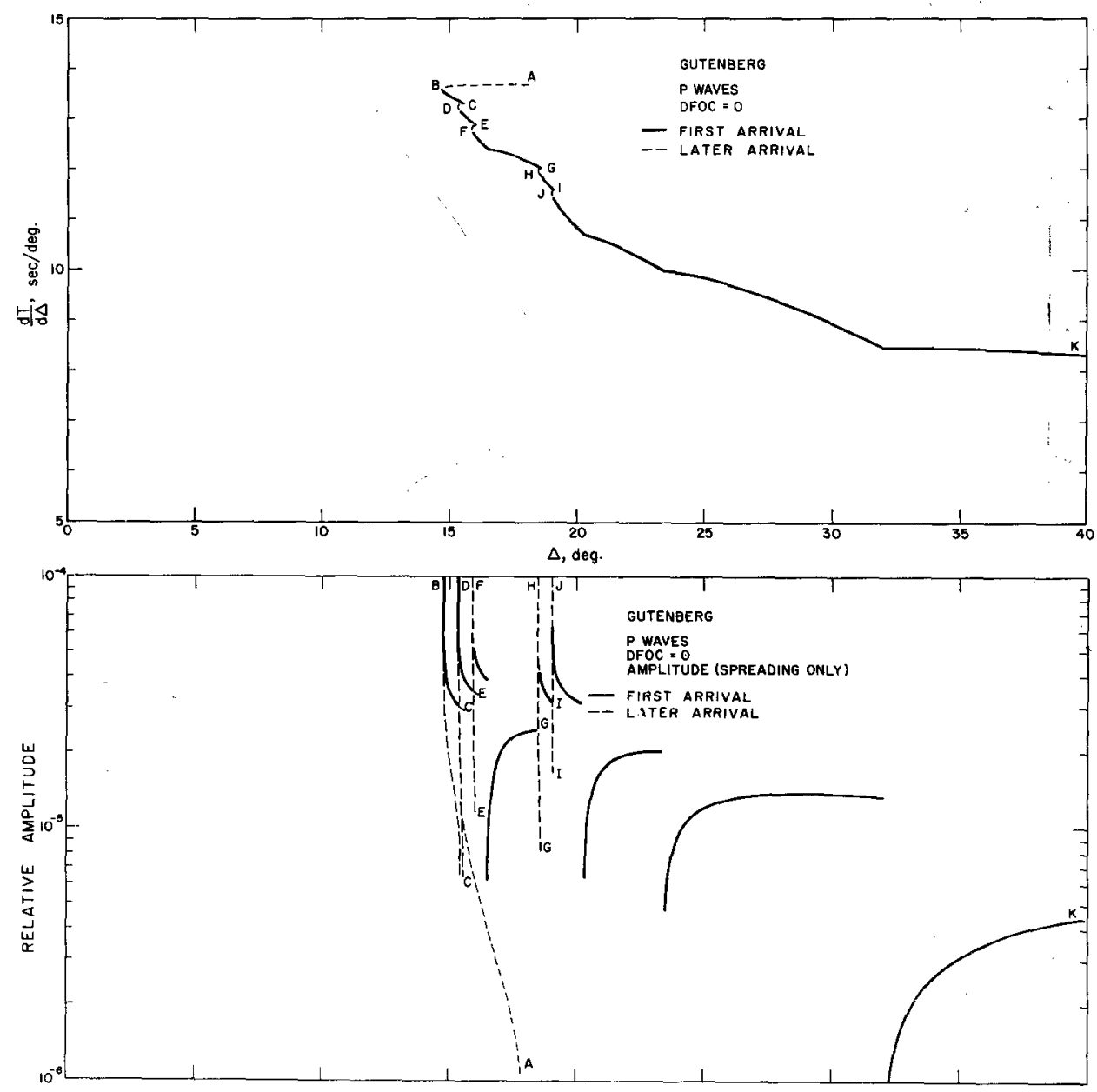

FIG. 16. $d T / d \Delta$ and amplitude considering geometric spreading only, for $P$ waves in Gutenberg Earth model. Surface focus. Letters are for correlation with Figure 15.

Only if due attention is paid to later arrivals can sharp first and second order discontinuities be detected with body waves. Otherwise relatively smooth structures with very broad transition regions result. Furthermore, all the models considered here have later arrivals whose amplitude is sometimes greater than that of the first arrival. For the surface wave model CIT11GB, the amplitude is less for the first arrival than for some of the later arrivals throughout the distance range $12^{\circ}$ to $36^{\circ}$ for both $P$ and $S$ waves. The large amplitude later arrivals help explain the 
scatter of data near the "20 discontinuity." For a model similar to CIT11GB later arrivals from small events could easily be mistaken for the first arrival.

\section{Analysis of Body Wave Data}

In order to look for the large later arrivals predicted for the surface wave model CIT11GB, seismograms of underground nuclear explosions at the Nevada Test

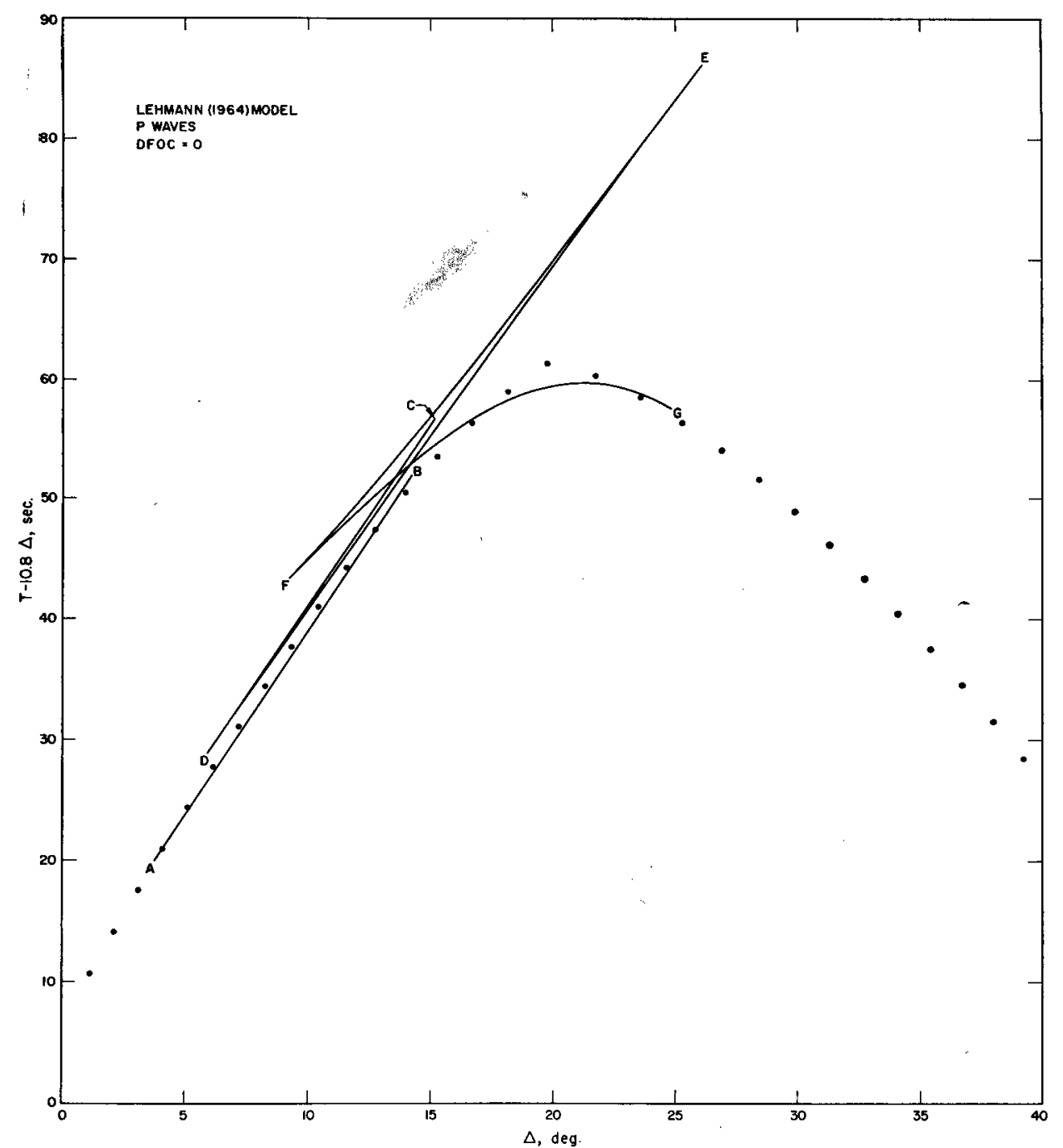

FIg. 17. Reduced $P$-wave travel times for Lehmann Earth model. Surface focus. Dots indicate Jeffreys-Bullen times. Letters are for correlation with Figure 18.

Site (NTS) recorded at the LRSM stations were examined, and those with the highest signal to noise at each station were selected. Figure 23 shows 7 of the best of these seismograms in the form of a record section for a rough profile extending NE from NTS. Figure 22 shows the location of the stations, as well as that of the 
NTS. A zone of triplication which begins at about $12^{\circ}$ with very large amplitudes and causes a sharp bend in the first arrival curve near $18^{\circ}$ is quite apparent on the seismograms. Also shown, though less clearly, is a second region of triplication, beginning at about $20^{\circ}$. This region produces a bend in the first arrival curve at about $24^{\circ}$ which is observed on other, longer profiles. The travel-time curve shown
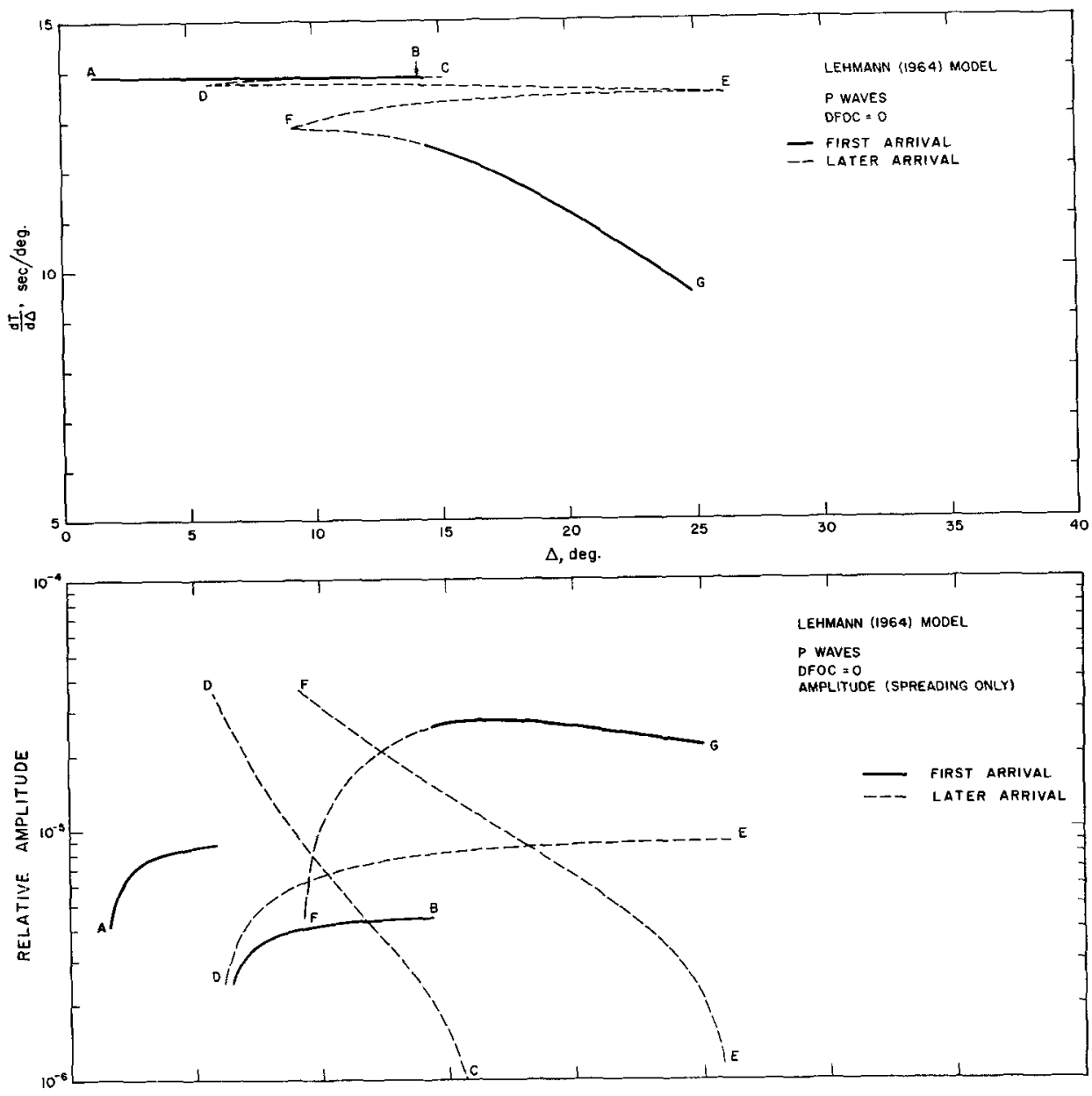

FIG. 18. $d T / d \Delta$ and amplitude, considering geometric spreading only, for $P$ waves in Lehmann Earth model. Surface focus. Letters are for correlation with Figure 17.

is for a version of Johnson's model CTT204 which has been modified slightly to satisfy these data. The original model CIT 204 of Johnson (1967), shown in Figure 24 was derived from direct measurements of $d T / d \Delta$ from earthquakes recorded at the Tonto Forest Seismological Observatory Array. It is a model appropriate for the western part of North America, and, in particular, the Basin and Range Province.

Another model, NTS-NE (19), which was derived by trial and error directly from the arrivals on the record section and satisfies the data equally well is also 


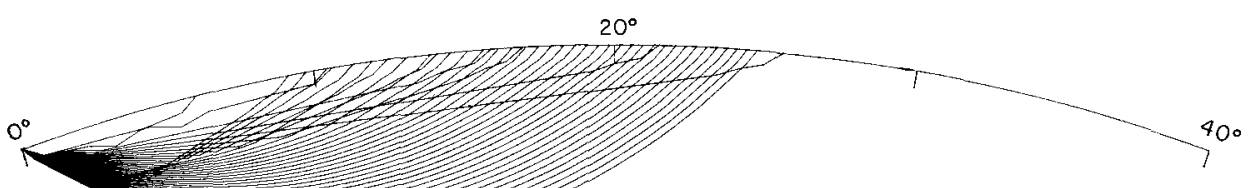

LEHMANN (1964) MODEL, P

$D F O C=0$

TOA $=34.5,0.5,55$

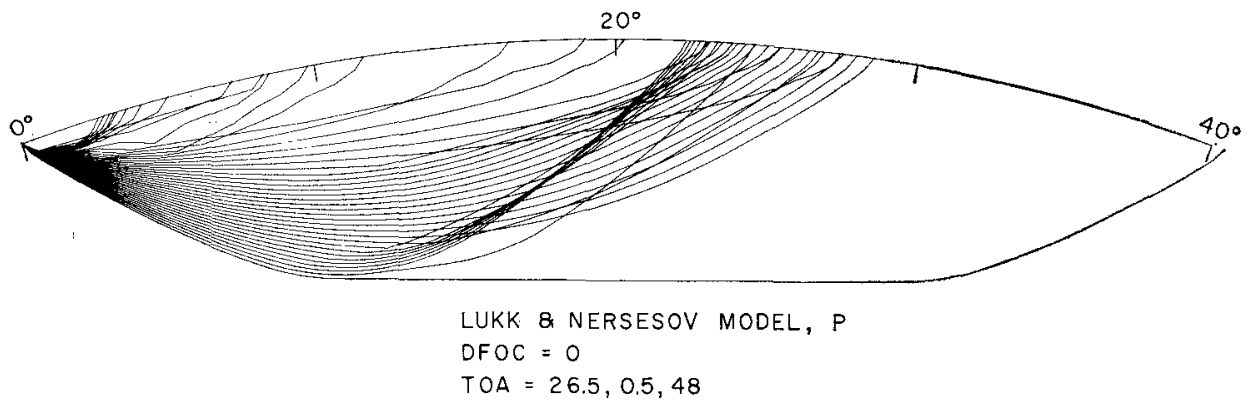

Fig. 19. Ray paths for $P$ waves in Earth models of Lehmann and Lukk and Nersesov.

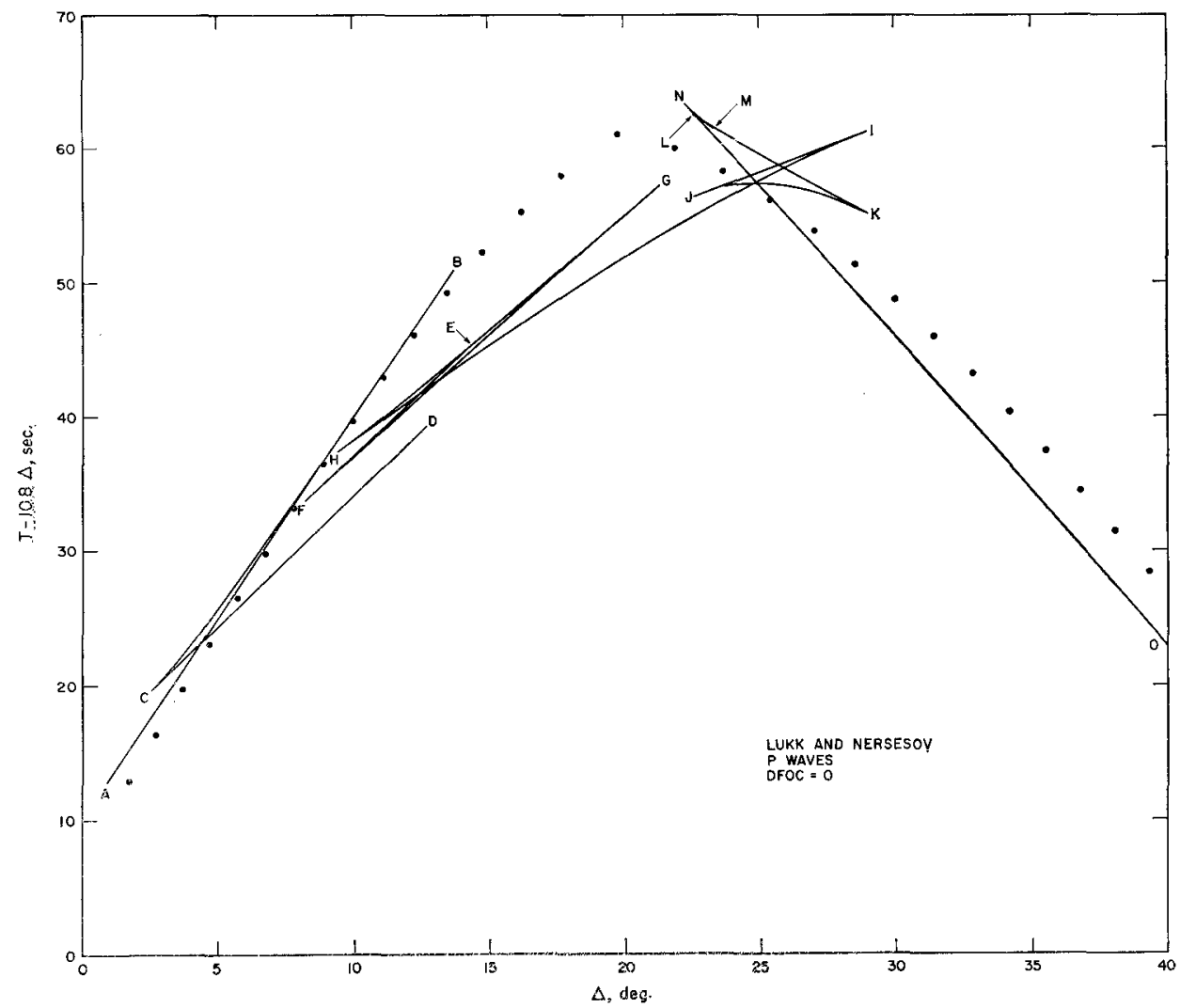

FIg. 20. Reduced $P$-wave travel times for Lukk and Nersesov Earth model. Surface focus. Dots indicate Jeffreys-Bullen times. Letters are for correlation with Figure 21. 
shown in Figure 24. It lacks the details of the other models since it is based on a very limited amount of data. All the models have transition regions starting near 400 and $600 \mathrm{~km}$ which are about $50 \mathrm{~km}$ thick. These are required to satisfy the large amplitude later arrivals which are apparent on the record section. The ray paths for the models are shown in Figures 25 and 26.
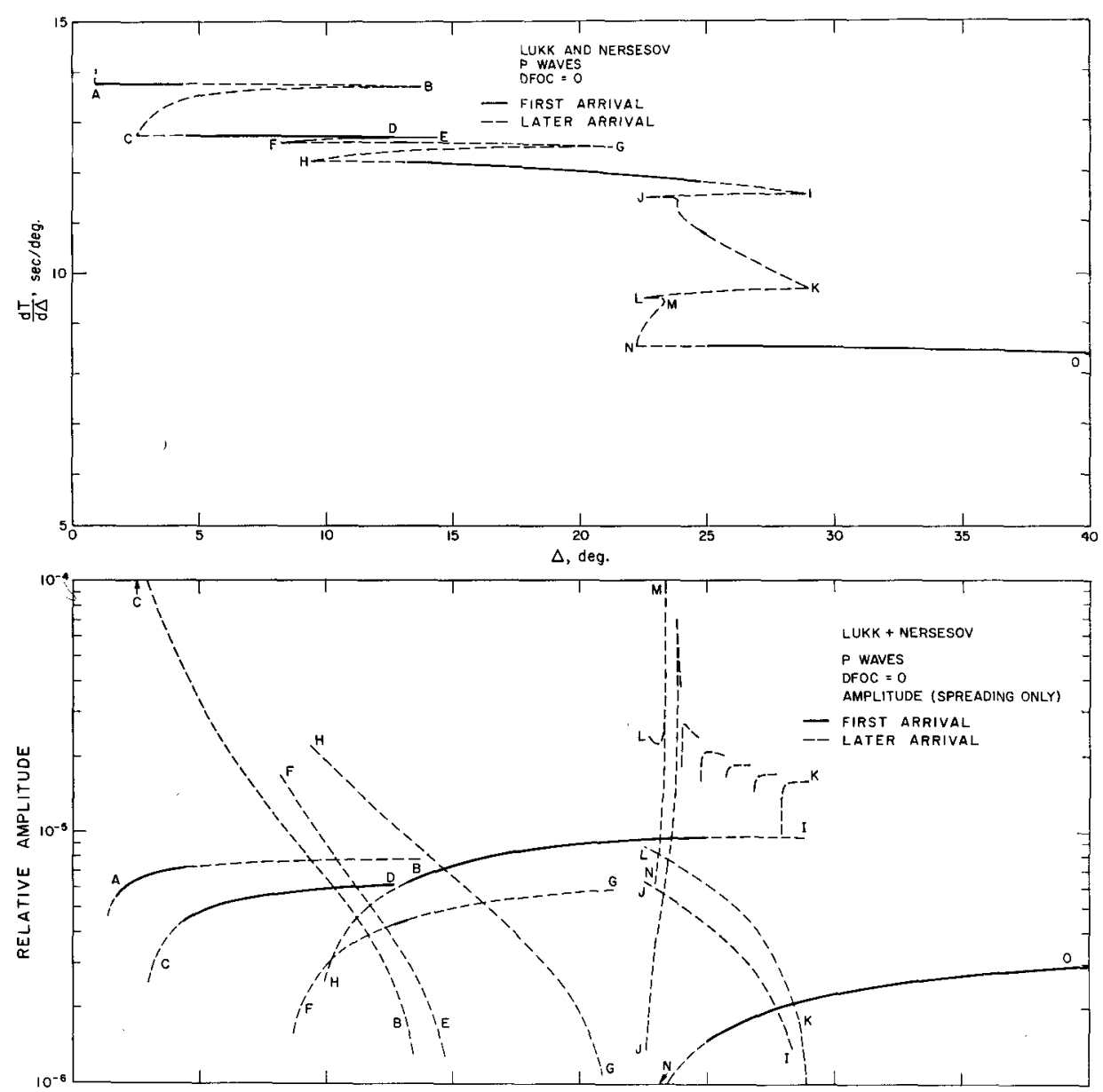

FIG. 21. $d T / d \Delta$ and amplitude, considering geometric spreading only, for $P$ waves in Lukk and Nersesov Earth model. Surface focus. Letters are for correlation with Figure 20.

A much more complete analysis of LRSM records from the events SHOAL and BILBY is in preparation by Archambeau, Flinn and Lambert (1967). Our purpose here is only to show that the discontinuities present in surface-wave models such as CIT11 are required by the body-wave data if due attention is paid to later arrivals.

The depths and thicknesses of the two transition regions are in excellent agreement with theoretical values for, first, the collapse of olivine to a spinel structure and then a phase change from the spinel to the oxide density (Anderson, 1967). 


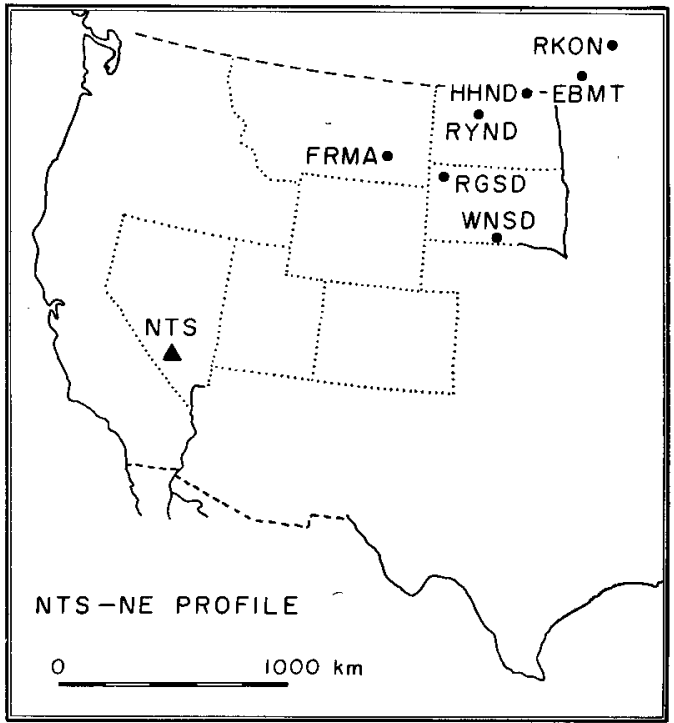

FIG. 22. Location of Nevada Test Site (NTS) and LRSM stations for which seismograms are shown in Figure 23.

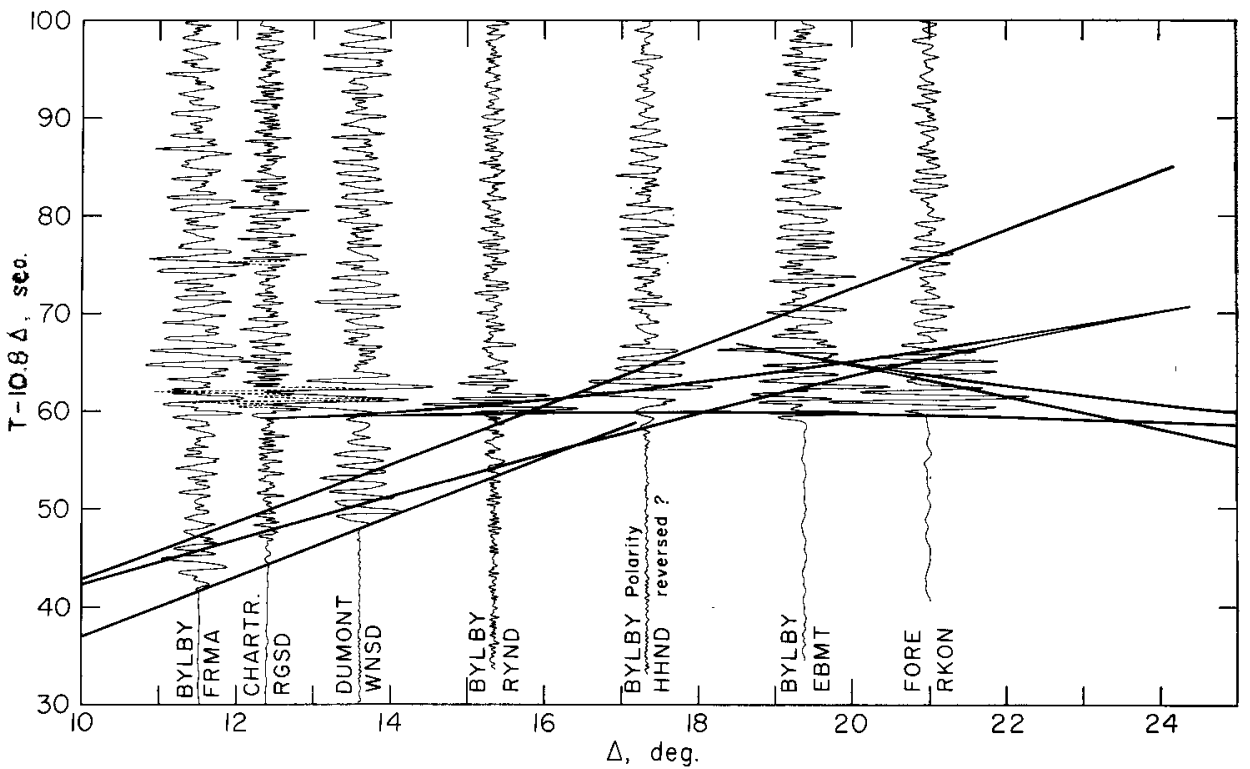

FIG. 23. Record section for NTS-NE profile (Figure 22).

\section{Body Wave Perturbation Theory}

The newer more detailed models of the upper mantle consistent with later arrivals, $d t / d \Delta$ and amplitude data are being combined with statistical studies of first arrival times to derive standard mantle models which will be used to generate tables of 
body wave parameters. These tables will complement the Jeffreys-Bullen tables and the revisions thereto which are in progress.

For regional studies it will be useful to be able to estimate the effect on the travel times which results from small changes in the standard model.

Referring to Figure 27, suppose curve $A$ is a portion of a travel-time curve for an

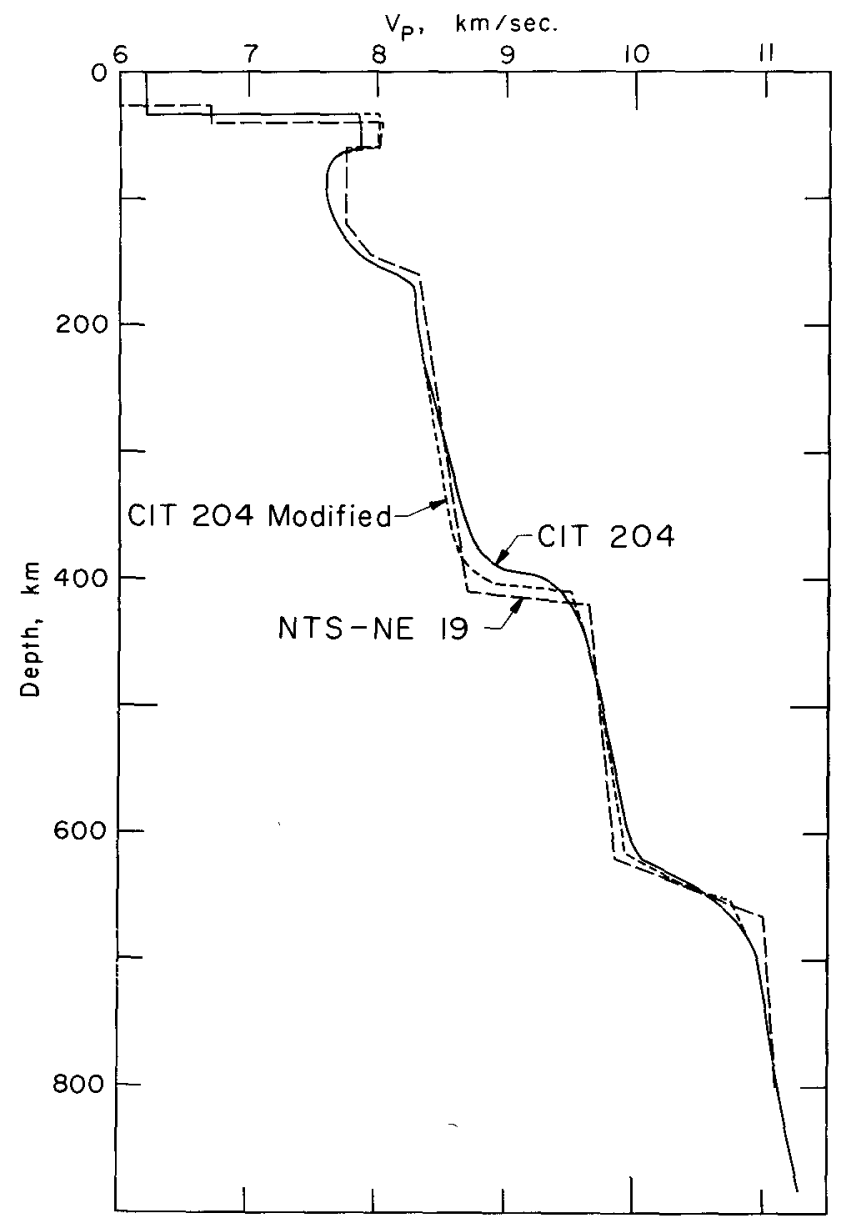

Frg. 24. Upper mantle $P$-wave velocity distribution for models CIT204, CIT204 modified, and NTS-NE 19.

initial earth model with velocity $v(r)$ and $B$ is the curve for a model with velocity $v(r)+\delta v(r)$, where $r$ is the radial coordinate. Further, suppose a ray, corresponding to a particular value of the ray parameter, $p$, emerges at point $a$ in the first case, and at point $b$ in the second case. Since $p=d T / d \Delta$, we see from the figure that, to first order:

$$
\delta(T)_{\Delta}=\delta(T)_{p}-p \delta(\Delta)=\delta(T-p \Delta)_{p} .
$$

The subscripts indicate that $p$ or $\Delta$, as the case may be, is held fixed. 

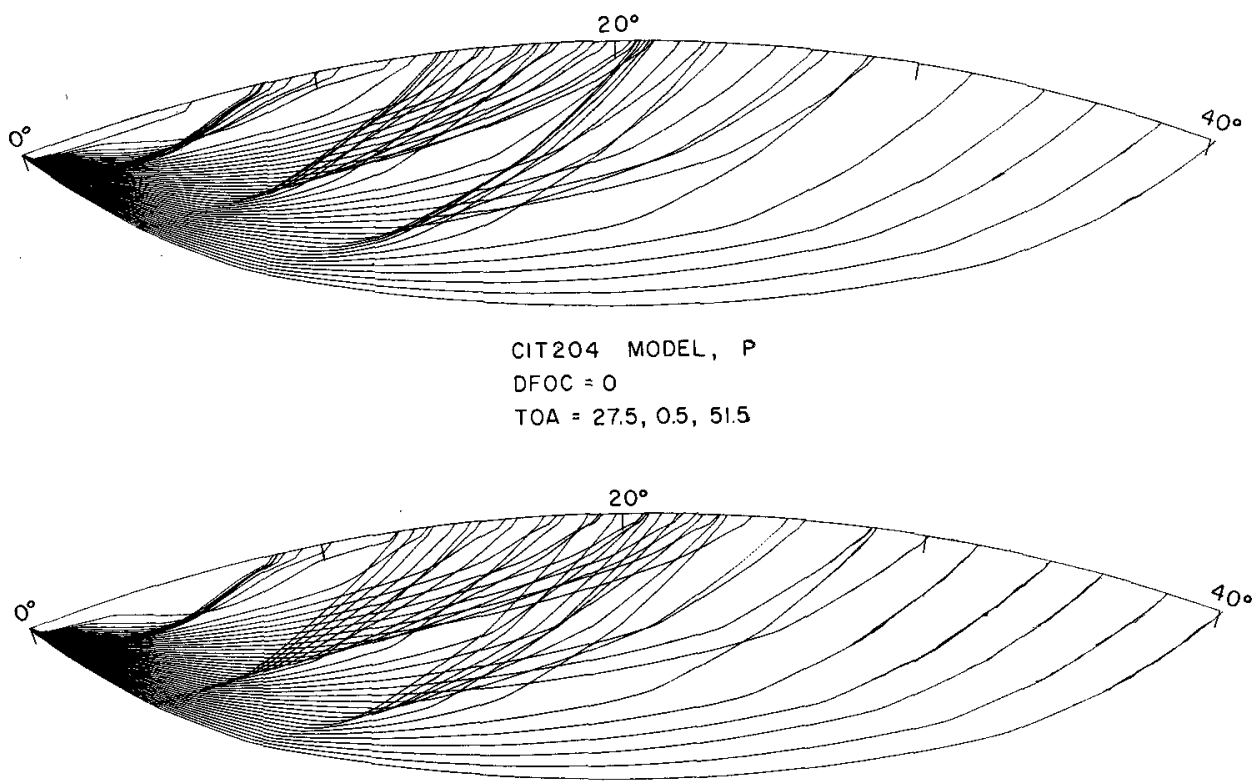

CIT2O4 MODIFIED MODEL, $P$

$\mathrm{DFOC}=0$

TOA $=27.5,0.5,50$

FIG. 25. Ray paths for $P$ waves in CIT204 and CIT204 modified Earth models.

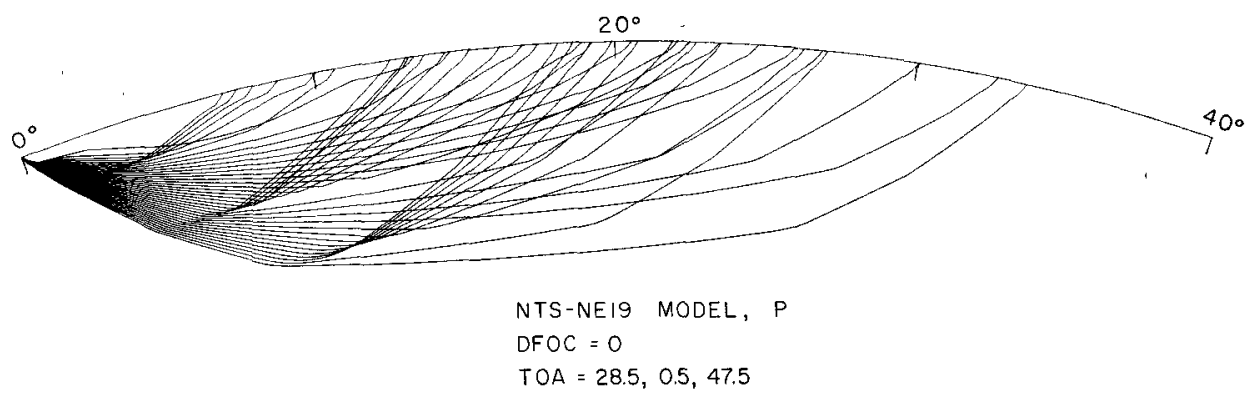

Fig. 26. Ray paths for Earth model NTS-NE 19.

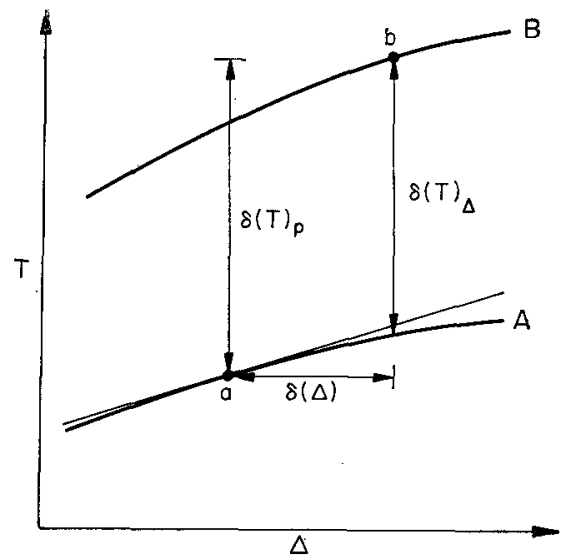

FIG. 27. Schematic representation of travel times for unperturbed (A) and perturbed (B) Earth models. $a$ and $b$ are points corresponding to same value of ray parameter, $p$. 
The standard integral formulas for $T-p \Delta$ and $T$ are, (Bullen, 1963, formulas (10) and (11), p. 112):

$$
\begin{aligned}
T-p \Delta & =2 \int_{r_{p}}^{R}\left(\frac{r^{2}}{v^{2}(r)}-p^{2}\right)^{1 / 2} \frac{d r}{r} \\
T & =2 \int_{r_{p}}^{R}\left(\frac{r^{2}}{v^{2}(r)}-p^{2}\right)^{-1 / 2} \frac{r d r}{v^{2}}
\end{aligned}
$$

where $R=$ Earth's radius

$r_{p}=$ radial coordinate at bottom of ray. From (2) we get

$$
\begin{aligned}
\delta(T-p \Delta)_{p}=-2 \int_{r_{p}}^{R}\left(\frac{r^{2}}{v^{2}(r)}-p^{2}\right)^{-1 / 2} & \frac{r}{v^{3}} \delta v d r \\
& -\left.\left.\frac{2}{r}\left(\frac{r^{2}}{v^{2}(r)}-p^{2}\right)^{1 / 2}\right|_{r=r_{p}} \frac{\partial r_{p}}{\partial v} \delta_{v}\right|_{r=r_{p}}
\end{aligned}
$$

The second term on the right vanishes, since $p=r_{p} / v\left(r_{p}\right)$, and, using (1) and (3)

$$
\delta(T)_{\Delta}=-\int_{s} \frac{\delta v}{v} d T
$$

where the path of integration, $s$, is the ray path. Archambeau and Flinn (1966) have derived essentially this same result. It follows from the fact that rays are minimum time paths, and could have been derived using the calculus of variations. It is valid, moreover, for a generally inhomogeneous body.

\section{Appendix: Method of Calculation}

Let the Earth be divided into $n$ spherical shells, in each of which the velocity is given by some analytic function of $r$, the radial coordinate, and some parameters $\mathfrak{a}_{i}$ :

$$
v=f\left(r, Q_{i}\right) \text { when } r_{i} \leqq r \leqq r_{i+1} \text { for } i=1,2, \cdots, n .
$$

Further, let $\Theta(\rho, Q, p)$ and $J(\rho, Q, p)$ be the angular length and travel time of a ray which makes a single passage from its deepest point to the surface in a sphere with radius $\rho$ and parameters $Q ; p$ is the conventional ray parameter. The angular length and travel time for a ray starting and ending at the surface of the earth are then:

$$
\begin{aligned}
& \Delta=2\left\{\Theta\left(r_{j+1}, \mathfrak{a}_{j}, p\right)+\sum_{i=j+1}^{n}\left[\Theta\left(r_{i+1}, \mathfrak{Q}_{i}, p\right)-\Theta\left(r_{i}, \mathfrak{Q}_{i}, p\right)\right]\right\} \\
& T=2\left\{\Im\left(r_{j+1}, \mathfrak{Q}_{j}, p\right)+\sum_{i=j+1}^{n}\left[\Im\left(r_{i+1}, \mathfrak{Q}_{i}, p\right)-\Im\left(r_{i}, \mathfrak{Q}_{i}, p\right)\right]\right\},
\end{aligned}
$$

Here $j$ is the index of the layer in which the ray bottoms. If the ray does not begin 
at the surface, then, of course, the contributions of some layers are deleted from the above summation. The amplitude of the emerging wave is determined by two effects: geometric spreading and attenuation. The effect of geometric spreading is given by

$$
\frac{E}{I}=\frac{v\left(r_{f}\right) \tan i\left(r_{f}\right)}{R^{2} r_{f} \sin \Delta \cos i(R)}\left|\frac{d^{2} T}{d \Delta^{2}}\right|
$$

(see, e.g., Bullen, 1963, ch. 8), where:

$E=$ power/unit area of wavefront at Earth's surface

$I=$ power/unit solid angle at source

$R=$ radius of earth

$r_{f}=$ radial coordinate of earthquake focus

$i=$ angle between ray and vertical.

The angle $i(r)$ is calculated from

$$
p=\frac{r}{v(r)} \sin i(r)
$$

Since $p=d T / d \Delta$,

$$
\frac{d^{2} T}{d \Delta^{2}}=\frac{d p}{d \Delta}=\frac{1}{d \Delta / d p}
$$

And, from (7)

$$
\frac{d \Delta}{d p}=2\left\{\frac{\partial \Theta\left(r_{j+1}, \mathfrak{Q}_{j}, p\right)}{\partial p}+\sum_{i=j+1}^{n}\left[\frac{\partial \Theta\left(r_{i+1}, \mathfrak{Q}_{i}, p\right)}{\partial p}-\frac{\partial \Theta\left(r_{i}, \mathfrak{Q}_{i}, p\right)}{\partial p}\right]\right\}
$$

enabling $d^{2} T / d \Delta^{2}$, and thus $E / I$, to be calculated.

The effect of attenuation is to reduce the energy in the wave by the factor

$$
\exp \left(-\omega \int \frac{d T}{Q}\right)
$$

where

$$
\begin{aligned}
& Q=\text { dimensionless quality factor } \\
& \omega=\text { angular frequency. }
\end{aligned}
$$

The integral is evaluated along the ray path. Since the time increment for each segment of the ray is available in the course of the travel-time calculations, evaluation of the integral, given $Q(r)$, is straightforward.

The depths and thicknesses of the two transition regions are in excellent agreement with theoretical values for, first, the collapse of olivine to a spinel structure and then a phase change from the spinel to the oxide density (Anderson, 1967). 
For both $P$ and $S$ waves, the amplitude is related to the power by

$$
E=1 / 2 \sigma v \omega^{2} A^{2}
$$

where:

$$
\begin{aligned}
\sigma & =\text { density } \\
A & =\text { amplitude }
\end{aligned}
$$

The amplitude thus calculated is that of the emerging wave; to calculate the surface motion, the effect of the reflected waves must also be considered. This has been done for a Gutenberg model by Landisman et al (1966).

Computer programs have been written which use two different velocity functions: $v=a-b r^{2}$ and $v=a r^{b}$. The corresponding functions for $\Im, \Theta$, and $\partial \Theta / \partial p$ are:

$v=a-b r^{2}$ :

$$
\begin{aligned}
& J(\rho, a, b, p)=\left\{\begin{array}{r}
\frac{\rho}{v(\rho)}\left(\lambda^{2}-1\right)^{-1 / 2} \sinh ^{-1}\left[\left(\lambda^{2}-1\right)^{1 / 2} \sin \Theta(\rho, a, b, p)\right] \\
\text { if } b>0 \\
\frac{\rho}{v(\rho)}\left(1-\lambda^{2}\right)^{-1 / 2} \sin ^{-1}\left[\left(1-\lambda^{2}\right)^{1 / 2} \sin \Theta(\rho, a, b, p)\right] \\
\text { if } b<0
\end{array}\right. \\
& \Theta(\rho, a, b, p)=\cot ^{-1}[\lambda \tan i(\rho)]=\cot ^{-1}\left[\frac{\lambda p v(\rho)}{\sqrt{\rho^{2}-p^{2} v^{2}(\rho)}}\right] \\
& \frac{\partial \Theta(\rho, a, b, p)}{\partial p}=-\frac{\cos ^{2} \Theta(\rho, a, b, p)}{p \lambda \sin i(\rho) \cos i(\rho)}
\end{aligned}
$$

where:

$v=a r^{b}:$

$$
\lambda=\frac{a+b \rho^{2}}{a-b \rho^{2}}
$$

$$
\begin{aligned}
\Im(\rho, a, b, p) & =\frac{\rho^{1-b}}{a(1-b)} \sin [(1-b) \Theta(\rho, a, b, p)] \\
= & \frac{1}{1-b} \sqrt{\left(\frac{\rho^{1-b}}{a}\right)^{2}-p^{2}} \\
\Theta(\rho, a, b, p) & =\frac{1}{1-b} \cos ^{-1} \frac{a p}{\rho^{(1-b)}} \\
\frac{\partial \Theta(\rho, a, b, p)}{\partial p} & =-\frac{1}{1-b}\left[\left(\frac{\rho^{1-b}}{a}\right)^{2}-p^{2}\right]^{-1 / 2} \\
& =-\frac{1}{(1-b)^{2} J(\rho, a, b, p)} .
\end{aligned}
$$

The values of $a_{i}, b_{i}, i=1, \cdots, n$ are calculated so that the velocity takes on specified values at the shell boundaries. For the velocity function $v=a r^{b}$, for example, we have in the $i$ th layer:

$$
\begin{aligned}
v\left(r_{i}\right) & =a_{i} r_{i}^{b_{i}} \\
v\left(r_{i+1}\right) & =a_{i} r_{i+1}^{b_{i}}
\end{aligned}
$$


which can be solved for $a_{i}$ and $b_{i}$ in terms of $r_{i}, v\left(r_{i}\right), r_{i+1}$, and $v\left(r_{i+1}\right)$ :

$$
\begin{aligned}
a_{i} & =\exp \left(\frac{\log v\left(r_{i+1}\right) \log r_{i}-\log v\left(r_{i}\right) \log r_{i+1}}{\log \left[r_{i} / r_{i+1}\right]}\right) \\
b_{i} & =\frac{\log \left[v\left(r_{i}\right) / v\left(r_{i+1}\right)\right]}{\log \left[r_{i} / r_{i+1}\right]} .
\end{aligned}
$$

It is also useful to be able to calculate the effect on the travel times of changing the parameters in each layer. This is simplest for the velocity function $v=a r^{b}$. From formulas (17) and (18) we get:

$$
\frac{\partial}{\partial a}(J-p \Theta)=-\frac{J}{a}
$$

which also follows immediately from (5). Also

$$
\frac{\partial}{\partial b}(\Im-p \Theta)=\frac{\Im-p \Theta}{1-b}-\Im \log \rho
$$

and

$$
\frac{\partial}{\partial \rho}(J-p \Theta)=\frac{1-b}{\rho} .
$$

With (5), (7), and (8) these partial derivatives could be used to calculate the effect on the total travel time of changing the model slightly. However, in regions where the velocity changes rapidly, the numerical value of $a$ may become very large, so it is preferable to calculate partial derivatives with respect to the values $r_{i}$, $v\left(r_{i}\right)$ specified by the user. From (20) and (21) we get, writing $v_{i}$ for $v\left(r_{i}\right)$

$$
\begin{aligned}
\frac{\partial a_{i}}{\partial v_{i}} & =-\frac{a_{i} \log r_{i+1}}{v_{i} \log r_{i} / r_{i+1}} \\
\frac{\partial a_{i}}{\partial r_{i}} & =\frac{a_{i} b_{i} \log r_{i+1}}{r_{i} \log r_{i} / r_{i+1}} \\
\frac{\partial b_{i}}{\partial v_{i}} & =\frac{1}{v_{i} \log r_{i} / r_{i+1}} \\
\frac{\partial b_{i}}{\partial r_{i}} & =-\frac{b_{i}}{r_{i} \log r_{i} / r_{i+1}}
\end{aligned}
$$

and similar expressions for $\partial a_{i-1} / \partial v_{i}, \partial a_{i-1} / \partial r_{i}, \partial b_{i-1} / \partial v_{i}$, and $\partial b_{i-1} / \partial r_{i}$. Now, using (5), (7), and (8) we get: (calling, for simplicity, $\chi(\rho, a, b, p)=\Im(\rho, a, b, p)-$ $p \Theta(\rho, a, b, p))$

$$
\left(\frac{\partial T}{\partial v_{i}}\right)_{\Delta}=\frac{\partial}{\partial v_{i}}(T-p \Delta)_{p}=\sum_{j=i-1}^{i}\left(A_{j} \frac{\partial a_{j}}{\partial v_{i}}+B_{j} \frac{\partial b_{j}}{\partial v_{i}}\right)
$$


and

$$
\begin{aligned}
\left(\frac{\partial T}{\partial r_{i}}\right)_{\Delta}=\frac{\partial}{\partial r_{i}}(T-p \Delta)_{p}= & \sum_{j=i-1}^{i}\left(A_{j} \frac{\partial a_{j}}{\partial r_{i}}+B_{j} \frac{\partial b_{j}}{\partial r_{i}}\right) \\
& -\frac{\partial}{\partial r_{i}}\left(\chi\left(r_{i}, a_{i}, b_{i}, p\right)-\chi\left(r_{i}, a_{i-1}, b_{i-1}, p\right)\right)
\end{aligned}
$$

where:

$$
\begin{aligned}
& A_{j}=\frac{\partial}{\partial a_{j}}\left\{\chi\left(r_{j+1}, a_{j}, b_{j}, p\right)-\chi\left(r_{j}, a_{j}, b_{j}, p\right)\right\} \\
& B_{j}=\frac{\partial}{\partial b_{j}}\left\{\chi\left(r_{j+1}, a_{j}, b_{j}, p\right)-\chi\left(r_{j}, a_{j}, b_{j}, p\right)\right\}
\end{aligned}
$$

and using (22)-(28) these become:

$$
\begin{aligned}
&\left(\frac{\partial T}{\partial v_{i}}\right)_{\Delta}=C-D \\
&\left(\frac{\partial T}{\partial r_{i}}\right)_{\Delta}=- \frac{b_{i} v_{i}}{r_{i}} C+\frac{b_{i-1} v_{i}}{r_{i}} D \\
&+\frac{1-b_{i-1}}{r_{i}} \Im\left(r_{i}, a_{i-1}, b_{i-1}, p\right)-\frac{1-b_{i}}{r_{i}} \Im\left(r_{i}, a_{i}, b_{i}, p\right) .
\end{aligned}
$$

where:

$$
\begin{gathered}
C=\frac{J\left(r_{i}, a_{i}, b_{i}, p\right)}{v_{i}}+\frac{\chi\left(r_{i+1}, a_{i}, b_{i}, p\right)-\chi\left(r_{i}, a_{i}, b_{i}, p\right)}{v_{i} \log \left(r_{i} v_{i+1} / r_{i+1} v_{1}\right)} \\
D=\frac{\Im\left(r_{i}, a_{i-1}, b_{i-1}, p\right)}{v_{i}}+\frac{\chi\left(r_{i}, a_{i-1}, b_{i-1}, p\right)-\chi\left(r_{i-1}, a_{i-1}, b_{i-1}, p\right)}{v_{i} \log \left(r_{i-1} v_{i} / r_{i} v_{i-1}\right)}
\end{gathered}
$$

\section{ACKNowledg Ments}

This research was supported by the Air Force Office of Scientific Research, Office of Aerospace Research, United States Air Force, under contract number AF-49(638)-1337. One of the authors (B. R. J.) was supported by a National Science Foundation Graduate Fellowship while engaged in this work.

\section{REFERENCES}

Anderson, D. L. and M. N. Toksöz (1963). Surface waves on a spherical earth. 1. Upper mantle structure from love waves, J. Geophys. Res. 68, 3483-3500.

Anderson, D. L., A. Ben-Menahem and C. B. Archambeau (1965). Attenuation of seismic energy in the upper mantle, J. Geophys. Res. 70, 1441-1448.

Anderson, D. L. (1967). Phase ehanges in the upper mantle, Science 157, 1165-1173.

Archambeau, C. B. and E. A. Flinn (1966). Perturbation Theory for the Inversion of Body Wave Travel Time Data, SDL Report no. 142.

Archambeau, C. B., E. A. Flinn and D. G. Lambert (1967). Fine Structure of the Upper Mantle, in preparation.

Bullard, E. C. (1957). The density within the earth, Verhandelingen van het Koninklijk Nederlandsch Geologish-Mijnbouwkundig Genootschap, Geologische Serie, Deel XVIII, 23-41.

Bullen, K. E. (1963). An Introduction to the Theory of Seismology, 3rd Edition, Cambridge University Press.

Gutenberg, B. (1959). Wave velocities below the Mohorovicic discontinuity, Geophys. $J$. Royal Astr. Soc. 2, 348-352. 
Jeffreys, H. (1962). The Earth, 4th Edition, Cambridge University Press.

Johnson, L. R. (1967). Array measurements of $P$ velocities in the upper mantle, $J$. Geophys. Res. 72, 6309-6325.

Landisman, M., Y. Sato and T. Usami. (1966). Propagation of Disturbances in a GutenbergBullen $A^{\prime}$ Spherical Earth Model: T'ravel Times and Amplitudes of $S$ Waves. American Geophysical Union, Monograph 10, 482-494.

Lehmann, I. (1964). On the travel times of $P$ as determined from nuclear explosions, Bull. Seism. Soc. Am. 54, 123-139.

Lukk, A. A. and I. L. Nersesov (1965). Structure of the upper mantle as shown by observations of earthquakes of intermediate focal depth, Doklady Akad. Nauk SSSR, Earth Sciences Sections, 162, 14-16.

Seismological Laboratory

California Institute of Technology

Pasadena, California

(Division of Geological Sciences Contribution No. 1483)

Manuscript received August 9, 1967. 